\title{
Ad Watch 3.o: Developing Audiovisual and Narrative Techniques for Engaging the Audiovisual Content of Political Advertising
}

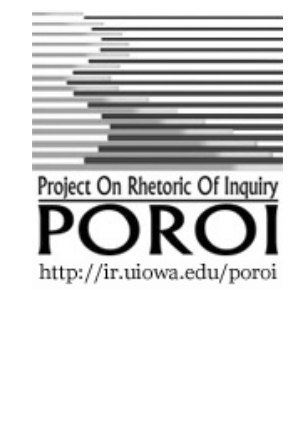

Glenn W. Richardson, Jr Dept. of Political Science, Kutztown University of Pennsylvania Kutztown, PA USA

Poroi 8,1 (April 2012)

In 1988, George Herbert Walker Bush's campaign advertisements claimed his opponent, Massachusetts Governor Michael Dukakis, was responsible for loosing hundreds of first-degree murderers on "weekend" passes, whereupon one of the furloughed convicts slashed a Maryland man and raped his fiancé. America, the Bush ad charged, could not afford to risk such leadership. The ads and the news coverage they spawned became a central part of the campaign narrative, abetted by Bush's frequent retellings of the tale on the campaign trail. The evidence of the lasting effect of the ads could be seen in the spike in references in the Congressional Record to "prison furloughs" the following year, and perhaps in Bush's own ascendancy to the White House. The ad's claims, however, were largely fraudulent. As Kathleen Hall Jamieson noted, only one furloughed inmate went on to commit other crimes such as rape, not the 268 suggested by the ad's juxtaposition of graphics and narrative. The prison furlough program had been initiated not by Dukakis, but by a Republican predecessor more than a decade earlier. Indeed Dukakis eventually abolished the furlough program after extensive reporting of the incident in question. Moreover the federal government, under the leadership of President Reagan and Vice President Bush, operated exactly the same kind of program. As a Dukakis ad pointed out, under that program, a convict escaped from a federal correctional halfway house and raped and killed a pregnant mother of two. The Massachusetts furloughs were not "weekend" passes but good for only 36 hours; even the name of the Massachusetts convict was twisted by Bush campaign spin: William J. Horton Jr. became "Willie Horton," the man Bush media consultant Lee Atwater promised to make "Michael Dukakis's running mate" (Jamieson 1992). Crime rates tend to ebb and flow, often impervious to public policy; but under Dukakis, Massachusetts had one of the lowest crime rates of any industrialized state in the nation.

\section{The Birth of the Ad Watch}

It was the media's complicity in the Bush tactics, however, that prompted perhaps the most significant and sustained critiques ever of press 
coverage of political campaigns and advertising in particular. Notably David Broder, one of the deans of the Washington Press corps, called for a greater effort to police the content of political spots (Broder 1990), a position also taken by academics including Jamieson and Darrell West (1992). The result was the growth of "ad watch" journalism (Ad Watch 2.0; see Richardson 2002). The 1992 presidential campaign produced a dramatic up-tick in media attention to campaign spots, including many specifically employing the visual grammar developed by Jamieson and her research team to allow reporters to critique an ad without reinforcing it's claims.

The initial results were encouraging. Candidates began to submit documentation to back up the claims made in their ads, and the ads themselves often included onscreen factual citations (West 2005:84). One television reporter argued that ad watch journalism was "the primary reason why no Willie Horton ads or their cousins have appeared in (the 1992) campaign. Our coverage is keeping the bastards honest" (Jamieson and Campbell 2001:332). Howard Kurtz of the Washington Post described the ad watches as "a great step forward for democracy," and a public opinion survey showed that 68 percent of those who responded found ad watches "somewhat helpful" or "very helpful" (West 2005:85).

\section{The Backlash: Let Lying Dogs Sleep}

Soon, however, the bloom would fall from the ad watch rose. In 1996, while print ad watches continued, television ad watches almost vanished. Network news producers claimed the Clinton-Dole contest was not close enough to justify the effort (Jamieson and Campbell 2001:332). Perhaps further fueling the turn away from the ad watch were the results of a high profile study by political scientists Shanto Iyengar and Stephen Ansolabehere that found ad watches almost wholly ineffective, even leading viewers to support candidates whose ads were being critiqued (Ansolabehere and Iyengar 1995; 1996). These findings prompted a reassessment of the ad watch project by prominent journalists, academics, and even some of the original proponents of the technique.

Writing in the New York Times Magazine, Max Frankel asked "whether it's worth chasing down the lies and slanders in the candidates' TV commercials," noting that "(o)ur Ad Watch campaigns seem to be giving wide circulation to 30 -second mendacities that the campaigns have paid us to air only once or twice." Specifically citing Ansolabehere and Iyengar's work, he continued, "(t)he now-routine policing of TV commercials, it turns out, often compounds the damage that those ads inflict on our democracy. We are being urged to pass up the temptations of testing the ads for truth, to let lying dogs sleep" (Frankel 1996:18). Washington Post columnist David Broder, an early advocate of the ad patrol, stated that the Ansolabehere and Iyengar findings "shatter some of my preconceptions," and that the evidence showed ad watches "appear only to reinforce the negative consequences. They 'clearly backfired"' (Broder 1996).

A host of other scholarly efforts produced at best mixed results on the efficacy of ad watches, some supporting claims of a "boomerang" or 
"backlash" effect (where the criticized ad sponsor actually gained support) (Pfau and Louden 1994; O'Sullivan and Geiger 1995; McKinnon and Kaid 1999; Leshner 2001). While West found an increase in ad watches in the New York Times and Washington Post in 2000 (compared to 1996), by 2004 the ad watch had become "an endangered species" (West 2005:88; see also Kaid, Tedesco and McKinnon 1996, Bennett 1997 and Weaver Lariscy and Tinkham 1999 on the decline of the ad watch in the 1990s).

\section{The Ad Watch Endures}

Perhaps, though, as with Mr. Twain, the rumors of the demise of the ad watch are greatly exaggerated. Even while on West's endangered species list (grounded in print and broadcast journalism), the ad watch seemingly flourished online and in other corners of the media environment during the 2004 campaign. Prominent ad watch sites included the Ad Watch component of PBS's "Politics 101," the Campaign Ad Watch section of MSNBC's "Decision 2004" web site, and perhaps the mother of all ad watch efforts, Factcheck.org (2004 features remain available in the site's archive). Separately, a group called "Best Practices in Journalism" sponsored over 20 workshops exploring different angles in election coverage including ad watches between 2000 and 2004. Though no longer active, group's web site features video clips of effective ad watch segments and tips for TV stations and reporters considering producing ad watch features. Still more ad watching occurred on independent web sites and blogs (see for example "Wonkette's" weblog on attack ads). All of this activity, moreover, pre-dated the existence of video sharing web sites such as YouTube and the anti-Bush video blog Political Zing. An Annenberg Public Policy Center study found a sharp increase in adwatch stories on TV during the mid-2000s compared to a decade earlier (Papper 2007). In 2008, Factcheck.org was joined in cyberspace by Politifact.com, a project of the St. Petersburg Times and Congressional Quarterly (featuring an "attack file" and a "truth-o-meter") and by "The Fact Checker" (from Washington Post blogger Michael Dobbs). Comedy Central's Indecision website frequently targets campaign spots as well (see also Painter and Hodges 2010 on Jon Stewart's role in holding the news media accountable).

In short, it is likely that future campaigns will see more, far more "ad watching" behavior by professionals and amateurs alike. The challenge in "building a better ad watch," therefore, no longer lies in finding appropriate venues for the task. Instead the key challenges are in the task itself, in effectively countering suspect elements of campaign commercials. Jamieson's pioneering efforts produced a "visual grammar" for ad critiques. Yet the grammar itself was a visual way of addressing the verbal and textual claims of ads. Still undeveloped are the tools and techniques that can address the audiovisual elements of ads. The role such elements play in how ads work may be substantial. Research emanating from the University of Iowa has spotlighted the way campaign ads rely upon the audiovisual conventions of popular culture and the recognizable genres from whence they spring to communicate both narrative and emotion (see for example Nelson and Boynton 1997; Richardson 2003). Michigan's Ted Brader found that emotionally 
uplifting music produced dramatic effects, increasing the likelihood of voting in viewers of his experimental campaign spots (Brader 2006). While ad watchers may have warmed to the task of truth-testing, even more challenging may be the need to assess the claims of character and characterization made in campaign communication. Just as audiovisuals often fly under the ad watch radar, so too do claims of character--even while such claims may be far more salient to ordinary citizens than the minutiae of policy that serves as the grist for the fact checkers' mill.

The present project is designed to explore the issues confronting the next generation of ad watches. It unfolds in three parts: first, an analysis of the limits and liabilities of extant journalistic approaches to campaign advertising, including the ad watch format. Second, demonstration of a handful of techniques that can aid those seeking to counter the questionable claims, assertions and implicit inferences of dubious political commercials. Finally, some brief ruminations on the future of the ad watch.

\section{Ads as News: Counterargument or Reinforcement?}

The scholarly research that began to cast doubt on the effectiveness of ad watch journalism highlighted the difficulty news producers have in attempting to counter the questionable claims and inferences in ads without unintentionally reinforcing the very charges they seek to rebut. Unfortunately, reporters, producers, and even researchers may have drawn the wrong conclusions from that scholarly evidence. For all the findings of the failure of ad watches, few have paused to consider the alternatives. The academic work was typically designed to measure whether ad watches worked in supplanting the claims of ads with the factual judgments of reporters. What they did not do was to contrast a world (more than just a broadcast) without ad watches to one with them. While one study that did contrast exposure to ad watches and exposure to the ads themselves found ad watches magnify the ad's messages, that work, like much of the research on ad watches, did not feature an ad watch pointing to major flaws in the ad (McKinnon and Kaid 1999), or fundamentally address the ad's audiovisual elements. In short, in testing the efficacy of ad watches, researchers, relying largely on extant ad watches, have used poor exemplars of the breed. They have focused narrowly, perhaps overlooking the broader implications of the ad watch movement.

While there can be little doubt that it is extremely difficult for journalists to counter the claims of campaign ads, academic efforts to assess the efficacy of the ad watch also have several drawbacks that have largely escaped scrutiny, even as the studies' conclusions may have influenced how journalists approach ads. None of the prominent analyses questioning the effectiveness of ad watch journalism involved random samples of Americans, or even of the residents of a given state. Several involved samples of undergraduates in communications-related courses. Many sought evidence that viewers would be repelled from a sponsor of an ad being analyzed when the actual ad analysis was not particularly 
critical (the closing line to the Brooks Jackson ad watch in the Iyengar and Ansolabehere study began, "Nothing really false here ...") (Jamieson and Cappella 1997; see also Richardson 2003:99-100). In their detailed response to the Ansolabehere and Iyengar work, Jamieson and Cappella conclude, "Ansolabehere and Iyengar's descriptions of the tested ad watches are themselves misleading ... No boomerang. No backlash" (Jamieson and Cappella 1997:19). All had to struggle with vexing issues of internal and external validity. Despite elaborate research designs aimed at simulating actual news in an on-going campaign environment, none truly comes close to replicating political behavior "in the field."

More broadly, ad watch research has implicitly adopted a primitive model of voting wherein all survey respondents are created equal, as are all survey responses. Marketers and political consultants now know that some respondents are more influential than others and have an outsized role in shaping the behavior of their peers. That is, the role of the reporter is to get information before the public. Individual members of the public naturally differ in their ability to parse information and to impart information to others. Moreover, the use of "online processing," (Hastie and Park 1986) where evaluations are made but the details supporting those judgments are discarded, may explain why less educated respondents may pick up the tone of an ad watch but do not retrieve specific information about it when probed by investigators, producing confounding effects for researchers (Jamieson and Cappella 1997:20).

In sum, it may be quite enough for journalists to make critical information available, whether or not experiments suggest that most respondents process that information properly. Once the information is available, an entire infrastructure of political communication comes into play, including parties and activists. The more important point is that there is a role for scholars, journalists and other observers to play in assessing the veracity of campaign communication, even absent scientifically compelling research findings on the efficacy of the effort. Scholarly work is grounded in professional norms but also seeks to serve broader public purposes. In that larger public sphere, the calling is deeper and the criteria for judgment more evasive. Yet, while truth is elusive, the quest for truth itself becomes instructive. Put another way, the quest for a truer campaign discourse need not be tethered to the survey respondent and the social scientist's t-test. As in so many public matters, action must proceed in the murky absence of complete information; time and again political behavior defies even the most sophisticated statistical modeling. The inadequacy of the disciplinary tools of scholarship does not eradicate the need for a more enlightened approach to assessing the honesty and integrity of the political campaigns at the core of electoral democracy. Noting the high level of misinformation among voters in a post-election survey following the 2008 campaign, Kathleen Hall Jamieson and Brooks Jackson of FactCheck.org reflected, "... are we discouraged that our efforts didn't prevent this? Not at all. If we hadn't tried, it might have been worse" (FactCheck.org 2008a). 
Correspondent Bob

McNamara begins the "Eye on America" feature by describing negative ads as "the bad breath of American politics." Next, MIT political scientist Stephen

Ansolabehere is shown in a soundbite, saying "the negative advertisements are very effective in raising doubts."

This is immediately followed by a clip from a Bush campaign ad (titled "Really?") showing Al Gore on a small kitchen-counter TV (canted to appear much like the ad images in ad watches), saying "I took the initiative in creating the internet." The ad clip qua news continues with a female voice over intoning "yeah, and I invented the remote control too."

The image of Gore on the little TV gives way to noisy static (conveying Gore's inauthenticity), first full screen, then within the countertop TV again (right), all straight from the Bush ad. Then, as correspondent McNamara says "as long as campaigns have come into the kitchen ..."

The Bush ad continues to play full screen, including the superimposed URL for the Bush web

site"gorewillsayanything.com " which appears (barely visible as a black line across the center of the image, at right) adjacent to the small TV with Gore on it, now shown from a distance, clearly revealing its
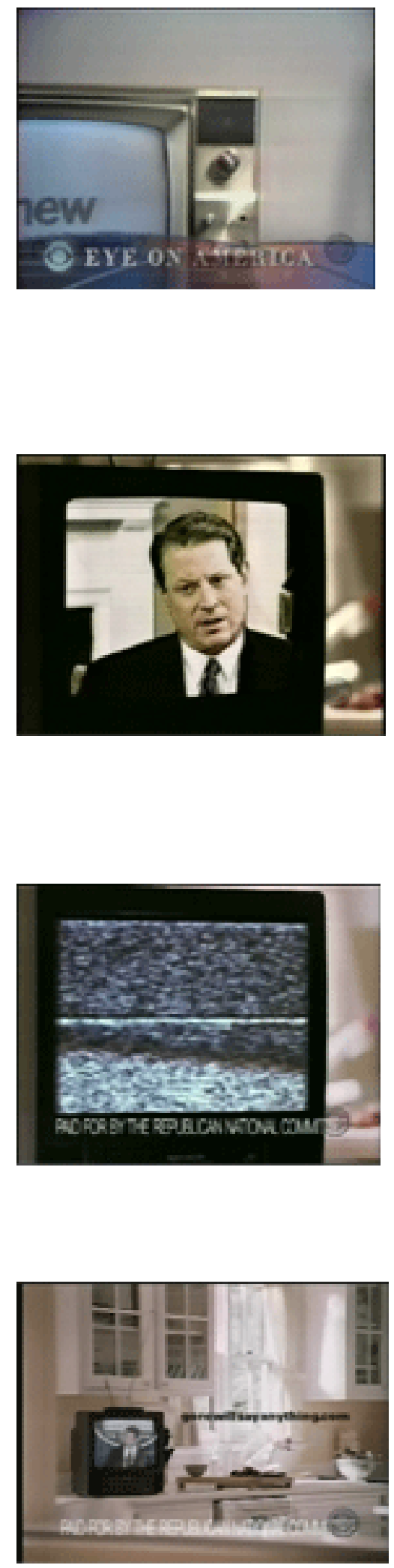
countertop location.

McNamara pauses slightly, and a clip from a 1988

Dukakis ad now plays. In this

clip, visibly titled in the ad as

"the packaging of Dan

Quayle," actors playing Bush

campaign consultants are

seen huddled around a table

with what appears to be

computer and video

equipment. The ad's

soundtrack fills the void left

by McNamara's pause: "that

debate was a disaster," says

one consultant. "Suddenly

the words President Quayle

even make me nervous,"

replies the other. Now

McNamara's voice returns:

"there have been negative

ads."

Next we see the distinguished communications scholar Lynda Lee Kaid stating "the all time high offender of negative ads, many people don't realize, I think, is Bill Clinton." Next, a clip from a 1992 Clinton ad showing in black lettering on a white screen the words "he asked you to believe him."

The ad's narration repeats the phrase, and then the ad's audio and video changes to Vice President Bush delivering perhaps his most infamous statement, "read my lips." The ad then shows the text "now he's asking you to believe his attacks against Bill Clinton." As the ad goes back to the audiovisual of Bush saying "read my lips," Professor Kaid's voice plays over the audio and video of the ad, still being shown. She says, "in his '92 campaign
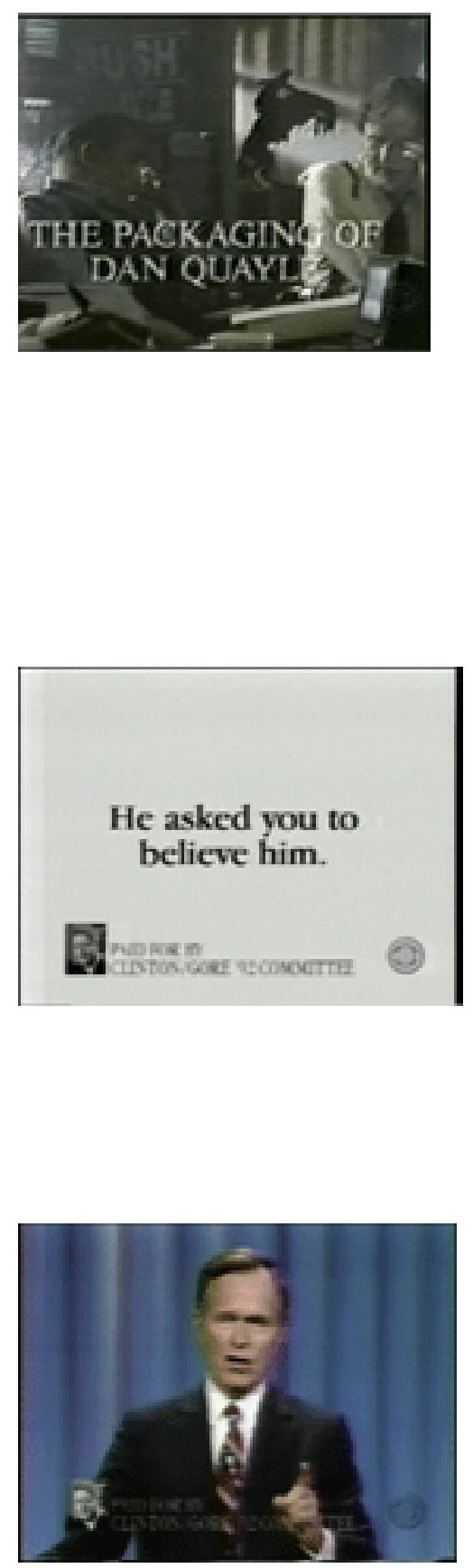
against George Bush," and then as she continues, the video returns from the ad to her speaking, "about 69 percent of all of his ads were negative."

The report continues with McNamara noting that George H. Bush himself had benefited from negative attacks, along with selfdescribed images of the "greatest hits (and misses)" of broadcast politics, including the 1988 Bush campaign's "Revolving Door" and 1964 Johnson "Daisy Girl" spots. The clip from "Revolving Door" includes the point at which that ad's narration and imagery combine to falsely suggest that 268 "first degree murderers not eligible for parole ... escaped" and went on to commit crimes such as rape and assault (only one such escapee committed such crimes, the infamous $\mathrm{Mr}$. Horton) (Jamieson 1992).

McNamara then notes (while more ads play in the background) that "women, sometimes the targets of the most unscrupulous attack ads, have turned the tables." Kaid, in voice-over, states, "women actually use negative ads more than men."

The segment concludes with a clip from an anti-Bush ad asking "is he ready to lead America?," then McNamara noting "going negative..."
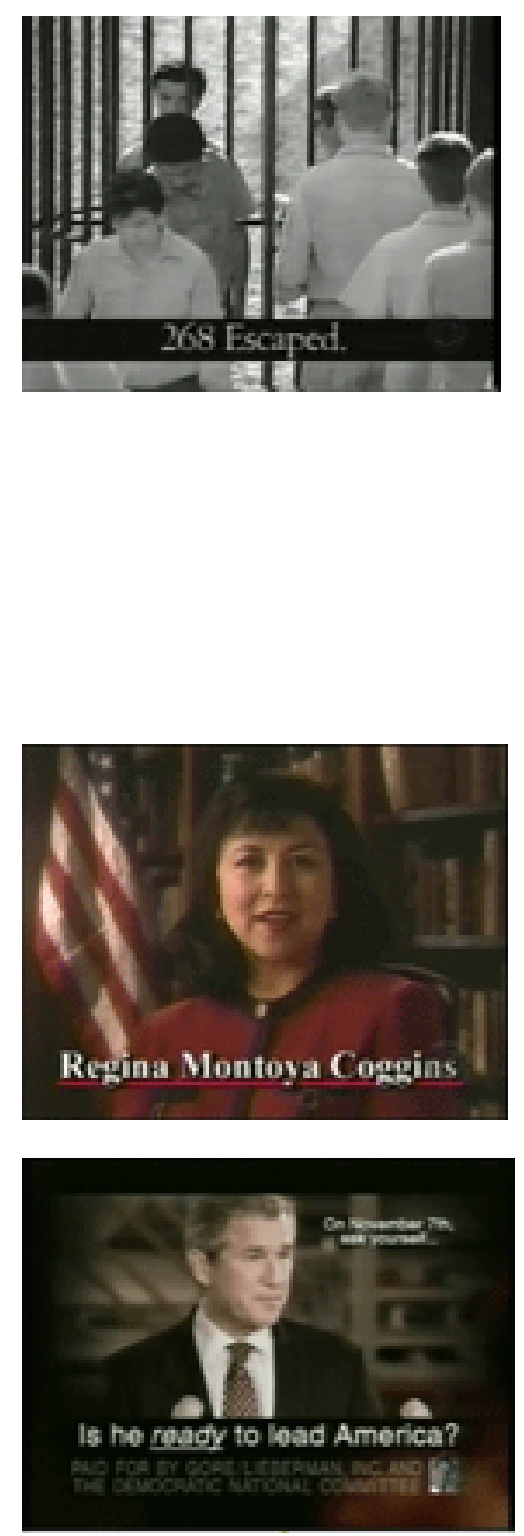
... as the video switches to Gore, in the Bush ad featured earlier in the segment, now framed by a white background with a cut-out in the shape of a TV screen, saying "there's never been a time when I've said something untrue," followed by the ad's punch line, stated by the ad's narrator and shown in black text on a white full screen: "Really?"

McNamara continues the narration as a new image from an anti-Bush ad appears "has often been the difference between winning and losing say the ad experts."

The video switches quickly from an anti-Bush to an antiGore ad ...
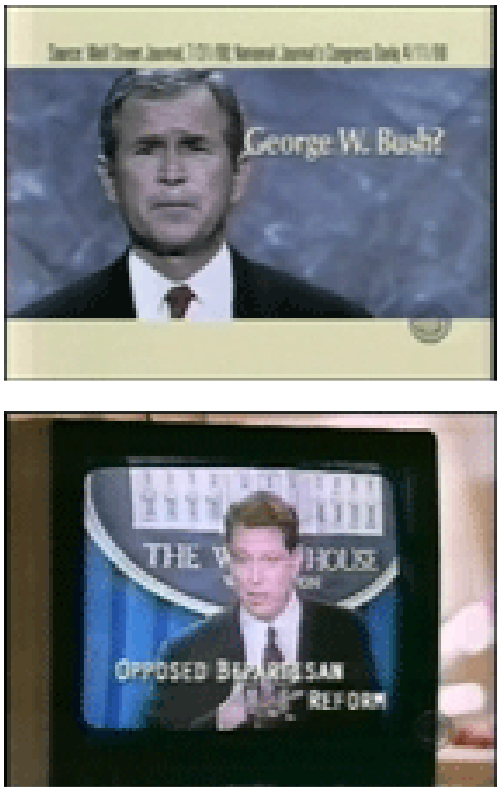

... before turning to an ad featuring chimps in shirts and ties poring over a budget, then doing back flips, as McNamara signs off: "and history is on their side..." Anchor Dan Rather chuckles and reminds viewers not to forget "to vote tomorrow."

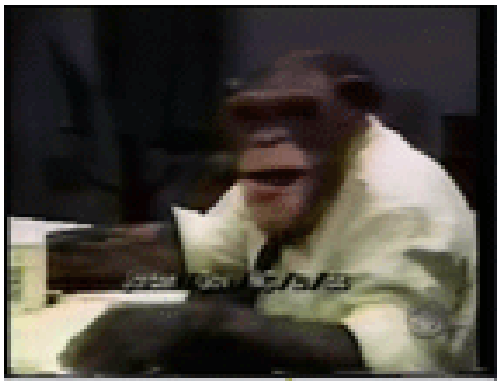

\section{Audiovisuals and the Ad Watch}

In building a better ad watch, perhaps the principal shortcoming is the lack of attention to the audiovisual claims made by ads (McKinnon et al 1996; Richardson 1998). This applies to ad watches and even more so to the use of ads in "regular" reporting. Consider the concluding story of the CBS Evening News on November 6, 2000. The story focused on "negative" ads, though no attempt was made to assess the validity of the 
claims made in the ad clips shown; though we are told such ads work to raise doubts, we are not told how.

\begin{abstract}
In its last story prior to Election Day 2000, this CBS Evening News "Eye on America" feature on negative advertising interspersed images from ads running in much of the nation at the time with expert commentary, magnifying the Bush campaign theme that $\mathrm{Al}$ Gore was untrustworthy. The segment also embraces the stereotypical disdain for "negative" advertising that permeates elite and mass discourse, while noting such spots "work." The feature illustrates much of what critics say is wrong with how the media covers political advertising. It uses unidentified full screen clips from campaign ads in news, leading viewers to confuse where they learned what, and may magnify the power of the ads shown--especially when they are woven into the fabric of the dominant narrative frames propagated by candidates and filtered by reporters and other observers. It focus on campaign strategy, not the veracity of the claims made in political ads.
\end{abstract}

(See associated File \# 1 to view)

The CBS feature managed to weave in three separate audiovisual clips from the Bush ad "Really?" that was then running heavily in selected media markets in the Midwest, East, and Pacific Northwest the night before the election. In fact, that ad would appear just 30 seconds after the close of the CBS Evening News on KYW channel 3 in Philadelphia, the fourth largest media market in the country. A slightly distracted viewer might look up at the TV one minute, see the CBS Evening News, see the Bush ad on the news and then look up again and see the Bush ad as an ad, albeit an ad itself designed to look like news. Moreover, Jamieson (1992) has noted how upon repeated viewings, merely showing part of an ad can induce recall of the whole of the ad.

All in all, a curious send off to the electorate the night before the vote from a newscast ostensibly serving the public interest. Of course the antipathy shown toward politicians in the feature may be more appealing to an audience itself already way past cynical. It was, though, a microcosm of the campaign coverage up to that point. Gore was a serial exaggerator.

Yet, even when reporters explicitly don their ad watch cloth, they generally fail to address the implicit audiovisual arguments. A Lexis-Nexis search of transcripts from the CBS Evening News suggests they never specifically discussed the Bush ad "Really?" which began airing in the final days of the campaign. Both the Washington Post and New York Times did include brief ad watch features on "Really?"

The ad is based on a story line that began on August 28, 2000, when Vice President Gore made a campaign stop at Florida State University in 
Tallahassee to push his health care agenda. After hearing several retirees describing the difficult choices they faced in trying to determine which medicines to buy, Gore called on the drug companies to lower prices. He offered as an example his mother-in-law, Margaret Ann Atchieson, who he said paid \$108 a month for the prescription arthritis medication Lodine, and his 14-year old labrador retriever Shiloh, whose prescription cost $\$ 39$ a month for the same drug. "It's pretty bad when you have got to pretend to be a dog or a cat to get a price break," Gore remarked. (see Robinson 2000a, 2000b; Wasson 2000).

Gore's appearance generated front-page coverage in Florida, but did not receive such prominent play nationwide. Then, on September 18, Boston Globe reporter Walter Robinson wrote a story arguing that Gore had "mangled the facts." Robinson reported Gore's aides could not say whether his mother-in-law took brand name Lodine or the generic equivalent; that the figures cited by Gore came not from family bills but from a House Democratic study; that the price comparisons erroneously assumed the same dosage; and that the prices were wholesale, not retail. Yet, Robinson noted, "(t)hose facts aside, Gore's overall message was accurate - that many brand-name drugs that have both human and animal applications are much more expensive for people than for pets." Indeed Robinson would note that the cost of prescription (brand name) Lodine "typically ranges from $\$ 140$ to $\$ 174$ a month . . . according to a Globe review of prices offered by walk-in and online pharmacies" and that the dog version (Etogesic), "costs at least \$70 a month for comparable doses" (Robinson 2000a). Indeed, "(a) check by The New York Times of several pharmacies and veterinary clinics in Washington found a price disparity between Lodine and Etogesic capsules roughly similar to that given by Mr. Gore" though the capsules were of different sizes (Seelye 2000).

Yet the press would soon be whipped up into a feeding frenzy, rising to the bait laid out on the issue by the Bush-Cheney campaign, which produced an 11-paragraph statement on the subject (Kelly 2000). This line was reinforced by public statements depicting Gore as someone who "makes up" facts to support his case, linked to repeated GOP claims that Gore routinely makes things up, like when had said he "invented" the internet. Bush Communications Director Karen Hughes claimed "that the vice president is willing to say anything to get elected" (Balz 2000). Vice presidential nominee Dick Cheney said Gore "simply makes some things up out of whole cloth and repeats them over and over and over again until he's called on it" (Cooper 2000). Governor Bush told one interviewer that Gore had a tendency "to make up facts to make his case," and that the episode "confirms what I have said in the past, that he'll say anything to be the president" (Seelye 2000). Bush stated in another interview, "a leader doesn't try to exaggerate in order to win" and that "America better beware of a candidate who is willing to stretch reality in order to win points" (Johnson 2000).

In the media, the Bush-Cheney campaign would find a willing accomplice. The bitter antipathy in the press toward Vice President Gore was longstanding and well known, dating back at least to Gore's response to queries about campaign finance during the 1996 Clinton-Gore 
reelection effort. Republican operatives seized upon the animosity already there and painstakingly fueled the notion of Gore as exaggerator through deliberate misrepresentations of Gore's statements (Parry 2000). By the fall campaign, the disdain was palpable, and it can be gleaned from USA Today columnist Walter Shapiro's take on Gore's prescription drug claims. He wrote, "(c)ampaigns do mete out a certain rough justice. If a candidate insists on being cloistered from both the press and the public, then he runs the risk that a minor snafu like the Shiloh affair may end up biting him in the leg" (Shapiro 2000). By the end of the week during which the story "broke," editorialists from coast to coast were piling on Gore for yet another exaggeration that cast doubt on his fitness to serve. Who knows where the story would have gone had reporters been aware that in fact Gore's mother-in-law's prescriptions were being filled for free by the White House physician (Shrum 2007)!

So it was that when the Bush-Cheney campaign released the ad "Really?," the ground had already been softened for the character assault that would follow.

\section{BUSH-CHENEY AD: "REALLY?"}

NARRATOR: Remember when Al Gore said his mother-in-law's prescription cost more than his dog's? His own aides said the story was made up. Now Al Gore is bending the truth again. The press calls Gore's Social Security attacks "nonsense." Governor Bush sets aside \$ 2.4 trillion to strengthen Social Security and pay all benefits.

VICE PRESIDENT GORE: There has never been a time when I have said something in this campaign that I know to be untrue. There has never been a time when I have said something untrue.

NARRATOR: Really?

(See Associated File \#2 to view)

In his ad watch, Washington Post media writer Howard Kurtz noted this was "perhaps (the) harshest" Bush attack during the campaign, that "Gore did not 'make up' the drug story but clearly misstated the facts," that "(t)he only 'press' cited as calling Gore's Social Security attacks nonsense is the Wall Street Journal's conservative editorial page," that the video of Gore was taken from a January debate, and even that "many newspapers have echoed Gore's criticism that Bush's Social Security plan threatens the budget surplus" (Kurtz 2000). In his single paragraph ad watch, Kurtz does an admirable job of identifying crucial flaws in the Bush ad's logic, though he notably does not address the interaction of narrative and video, failing to mention, for example, that the ad makes it appear that Gore is denying ever having said anything untrue during the campaign in "real time," i.e., the recent days after the fall presidential debates, and after the latest feeding frenzy over his "pattern of embellishment." He does note 
that the "sarcastic tag line softens the attack," but never explicitly explains that the joke itself is based on a fraudulent audiovisual juxtaposition, and how much the joke is central to the emotional impact of the ad. While he noted that Gore didn't "make up" the dog drug story, he didn't mention that those are the very words the Bush-Cheney ticket had been relentlessly (and by Kurtz's own analysis, erroneously) tarring Gore with since the publication of the Boston Globe piece.

Peter Marks (2000) ad watch in the New York Times does show sensitivity to the ad's emotional core, though it does far less to clarify the flaws in the Bush claims while amplifying its effects. He wrote, "(t)he spot is funny, devastating" and that "it cleverly changes the subject by suggesting that Mr. Gore's attacks are merely further evidence of a propensity for stretching the truth." (The ad was a response to Gore ads featuring Nobel Prize winning economists claiming Bush's Social Security plans would lead to huge budget deficits.) Marks concludes, "(t)he spot's payoff is the mocking clip in which Mr. Gore asserts that 'there has never been a time' when he uttered an untruth, and the announcer's cynical comeback. The commercial deftly shifts the focus from whatever doubts voters may have about Mr. Bush's proposal to questions about Mr. Gore's character." Marks seems unaware of the implication of Gore's remark being taken chronologically out of context; he adopts the Republican frame of Gore as serial exaggerator unquestioningly; fails to challenge the Bush language that Gore's misattribution of the source of the drug price quotes means he "made up" the story; chooses not to distinguish between "the press" and the editorial page of the Wall Street Journal; and apparently finds no fault in shifting debate from the trillions of dollars at issue in the Bush Social Security plan to the few dollars worth of exaggeration in the Gore drug price remarks on the basis of "funny ... clever .. .mocking . . . cynical" advertising that "deftly" weaves distortion and falsehood.

Arguably, "Gore as exaggerator" became a greater exaggeration than Gore's original exaggerations. What are we to think, moreover, of a campaign operation so ruthlessly and relentlessly dedicated to misrepresentation? And of a press so cynical and skeptical as to be readily manipulated by campaign operatives? In hindsight, one might claim that the nation would have been better served if the press had zeroed in on the Bush-Cheney campaign's manipulation of facts and events and what it said about how they would govern. Alas, such efforts would no doubt have met fierce cries of bias, an institutional conundrum from which no easy escape avails itself to reporters. Yet, in focusing instead on the character flaws of Gore, the press downplayed the character flaws of Bush, and in neither case was the notion of character sufficiently engaged.

The task facing the prospective ad watcher is daunting. What more could be done? Regarding audiovisual distortion, at least one possibility is suggested by political scientist Edward Tufte, a renowned expert on visual representation of data. He wrote:

One way to enforce some standard of truth-telling is to insist that the innocent, unprocessed natural image be shown along with the manipulated image, and, further, that the manipulators and their 
methods be identified. If images are to be credible, their source and history must be documented. And, if an image is to serve as serious evidence, a more rigorous accounting should reveal the overall pool of images from which the displayed image was selected. (1997:25)

In this case, a variation on this theme might be to reproduce the Bush ad so that the audiovisual distortion of the chronology of events is removed. That is, one could edit the ad so that Gore's remarks, the Bush ad claims and so on, were presented in the order in which they actually occurred, rather in the misleading order presented in the ad. Figure shows what such a "re-mixed" ad might look like.

\section{"REALLY?" RE-MIX}

This edit of the Bush-Cheney ad "Really?" includes every frame from the original ad, but an attempt has been made to place all events in proper chronological order. This serves to essentially reverse the ad's punch line, turning it on Governor Bush's claims to "pay all benefits" under his Social Security changes. Such editing could be combined with other audiovisual elements of an effective ad watch (such as labeling false claims), or one could "edit the edit" and just leave what's left of the argumentative core of the Bush ad when it has been stripped of its distortion and distraction--i.e., just show the part saying Bush will pay all benefits, followed by the sneering "Really?" punch line.

(See Associated File \#3 to view)

As much as anything, the "'Really?' Re-mix" demonstrates how hard it is to objectively critique the visual claims in campaign advertising without reinforcing the very object of critique. The remix also demonstrates, however, that if an ad's fundamental persuasive appeal is based on misleading visual context, that can be addressed. The re-mix is both less coherent and a better representation of the legitimacy of the ad's audiovisual "argument."

Dealing with the audiovisual elements of ads is clearly the biggest challenge facing the ad watcher, assuming one can find a way through the conflicting claims of partisans who can disagree vehemently over the correct time of day. One aspect of that challenge involves determining the proper frame of reference from which to assess audiovisual claims. In televised political advertising, the key audiovisual referents may well be those of popular culture and character (Nelson and Boynton 1997; Richardson 1998). This can be illustrated by considering the Bush-Cheney advertising in 2004. 


\section{The 2004 Bush-Cheney Ad Campaign: The Consistency of Character and the Character of Consistency}

In their bid to win a second term, at a broad level the Bush-Cheney campaign followed two interrelated tracks. The first would seek to reinforce the president's definition of himself as a "war president." The second was aimed at discrediting opponent John Kerry as the unreliable opposite to Bush's steadfast leadership, particularly on the key issue of security. To accomplish these objectives, Bush cultivated fear about the future and fear about Senator Kerry. The Bush camp ran several ads extensively on these issues, including "Peace and Security," "Searching," and "Risk." (Other ads also touched on these themes, including "Wolves," which echoed the Reagan-Bush ad featuring "a bear in the woods."). Taken together, they presented voters a world ripped from the world of Jack Bauer, the fictional superhero of the FOX action-thriller "24."

The ads "Peace and Security" and "Risk" juxtapose scenes of domestic tranquility (often personified in the faces of children) with ominous warnings about the terrorist threat and accusations that Senator Kerry and "liberals in Congress" voted to slash intelligence funds "after the first Trade Center attack," and opposed weapons vital to the war on terror. "Risk" also claims Kerry opposed "Reagan as he won the Cold War," and notes Kerry's opposition to the first Gulf War. "Peace and Security" says Kerry "refused to support our troops in combat with the latest weapons and body armor." Factcheck.org found the ads' claims false or distorted in virtually all of the particulars. They noted that the ads make it sound like Kerry voted to "slash" intelligence after the September 11 attack on the World Trade Center, when the "first attack on the Trade Center" occurred in 1993. Kerry's proposals to cut roughly 1 percent from the intelligence budget came five days after the Washington Post had reported that one intelligence agency, the super-secret National Reconnaissance Office, had quietly hoarded between $\$ 1$ billion and $\$ 1.7$ billion in unspent funds without informing the Central Intelligence Agency or the Pentagon. The CIA was in the midst of an inquiry into the NRO's funding because of complaints that the agency had spent $\$ 300$ million on unspent funds from its classified budget to build a new headquarters building in Virginia a year earlier. ... Also, the very same day Kerry proposed his $\$ 1.5$ billion cut, the Senate passed by voice vote an amendment proposed by Republican Senator Arlen Specter of Pennsylvania to eliminate $\$ 1$ billion in intelligence funds for fiscal year 1996. Specter made clear he was attempting to recoup $\$ 1$ billion in unused intelligence funds from the NRO .... (http://www.factcheck.org/article153.html)

Bush-Cheney charges that Kerry voted against weapons vital to the war on terror, Factcheck noted, were equally distorted. Kerry did oppose certain strategic weapons (such as the MX missile and B-2 Stealth bomber) but both were also abandoned by George H.W. Bush in his 1992 State of the Union Address in which he also announced plans for a 30 percent reduction in military spending. The Bush campaign identified the AH-64 Apache helicopter as another vital weapon opposed by Kerry even while Dick Cheney proposed canceling the same weapon five years after 
Kerry had. Other weapons "opposed" by Kerry were part of larger spending bills; Kerry never voted against the specific weapons he is charged with opposing in the Bush ads. Kerry was also correct in claiming to have "voted for some of the largest defense and intelligence budgets in our history." In fact, Kerry voted for every regular defense authorization bill since 1997, and did so in 16 of the 19 years he had served in the Senate. (http://www.factcheck.org/article147.html; http://www.factcheck.org/article177.html).

In some ways, the claim that Kerry opposed body armor for the troops is the most vicious of all. Kerry never voted specifically against body armor. His vote against the $\$ 87$ billion supplemental spending bill for Iraq that included body armor funds was coupled with his support of a bill to provide the same support while paying for it with tax increases on the wealthiest 1 percent of Americans. Kerry's legislative positioning translated miserably into his "I voted for the $\$ 87$ billion before I voted against it" comment that was immediately and incessantly broadcast in Bush-Cheney ads. Lost in the translation was the fact that it was President Bush that had sent the troops to Iraq in the first place without providing sufficient funds for body armor (http://www.factcheck.org/article15.5.html).

On the merits, then, the specific claims of the Bush-Cheney campaign amount to a pattern of outright falsehoods and grotesque distortions. And while the ad cops at Factcheck.org set the facts straight, they rarely addressed the audiovisual reinforcements of the ads master narrative. Those elements were substantial on their own.

\section{BUSH-CHENEY AD: "RISK"}

NARRATOR: After September 11th, our world changed. Either we fight terrorists abroad or face them here. John Kerry and liberals in Congress have a different view. They opposed Reagan as he won the Cold War. Voted against the first Gulf War. Voted to slash intelligence after the first Trade Center attack. Repeatedly opposed weapons vital to winning the War on Terror. John Kerry and his liberal allies. Are they a risk we can afford to take today?

PRESIDENT BUSH: I'm George W. Bush and I approve this message.

(See Associated File \#4 to view) 


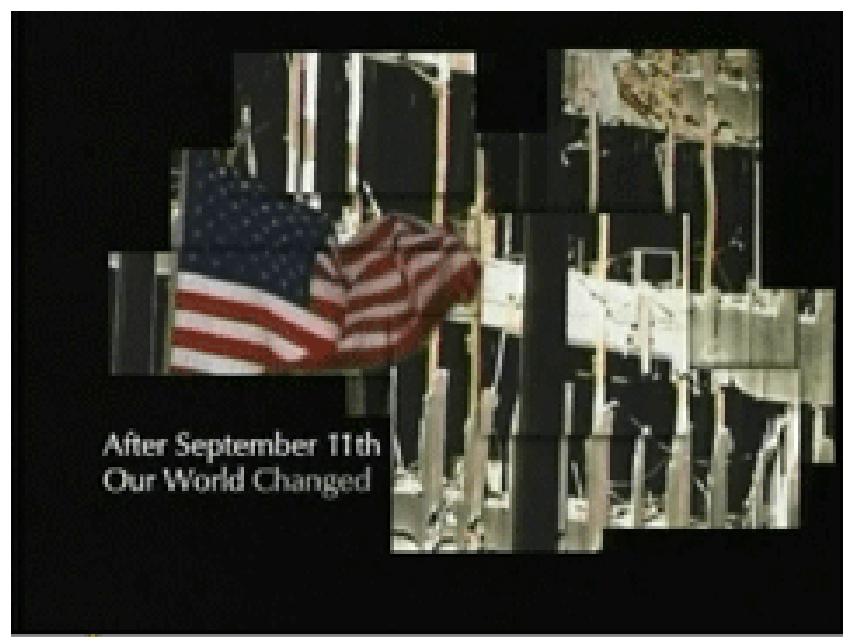

"Risk" begins with an image from Ground Zero after the September 11 attack on the World Trade Center with an American flag flying in the wind. The image is chopped into various sized squares and rectangles, each of which can be replaced by either a black box or image. The Ground Zero imagery may prime viewers to think of September 11, 2001 when several seconds later they hear the narration about Kerry favoring cuts in intelligence "after the first Trade Center attack," (emphasis added) which sounds to the ear a lot like "after the World Trade Center attack." The independent boxes within the video echo the use of simultaneous video windows in "24."

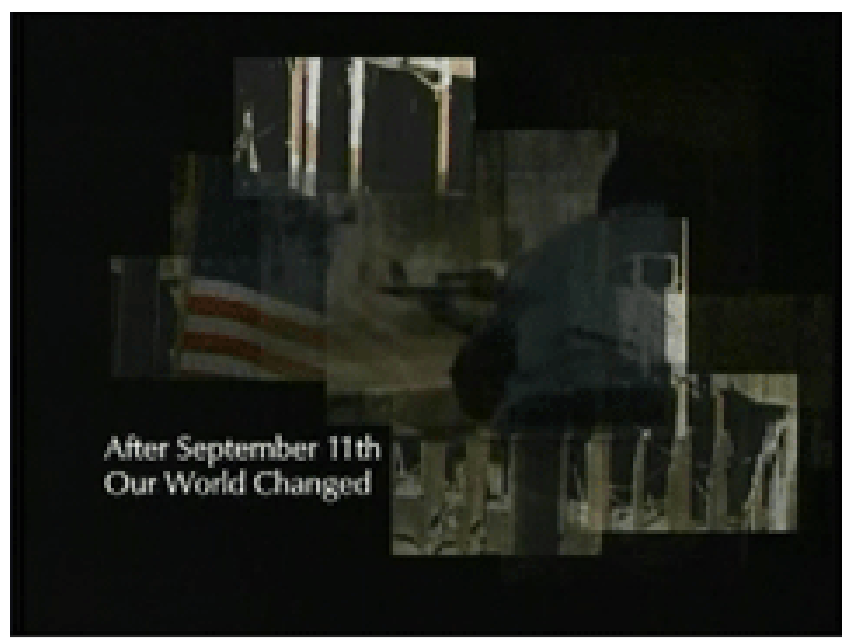

A fade transition joins the Ground Zero image with that of an armed, masked terrorist. 

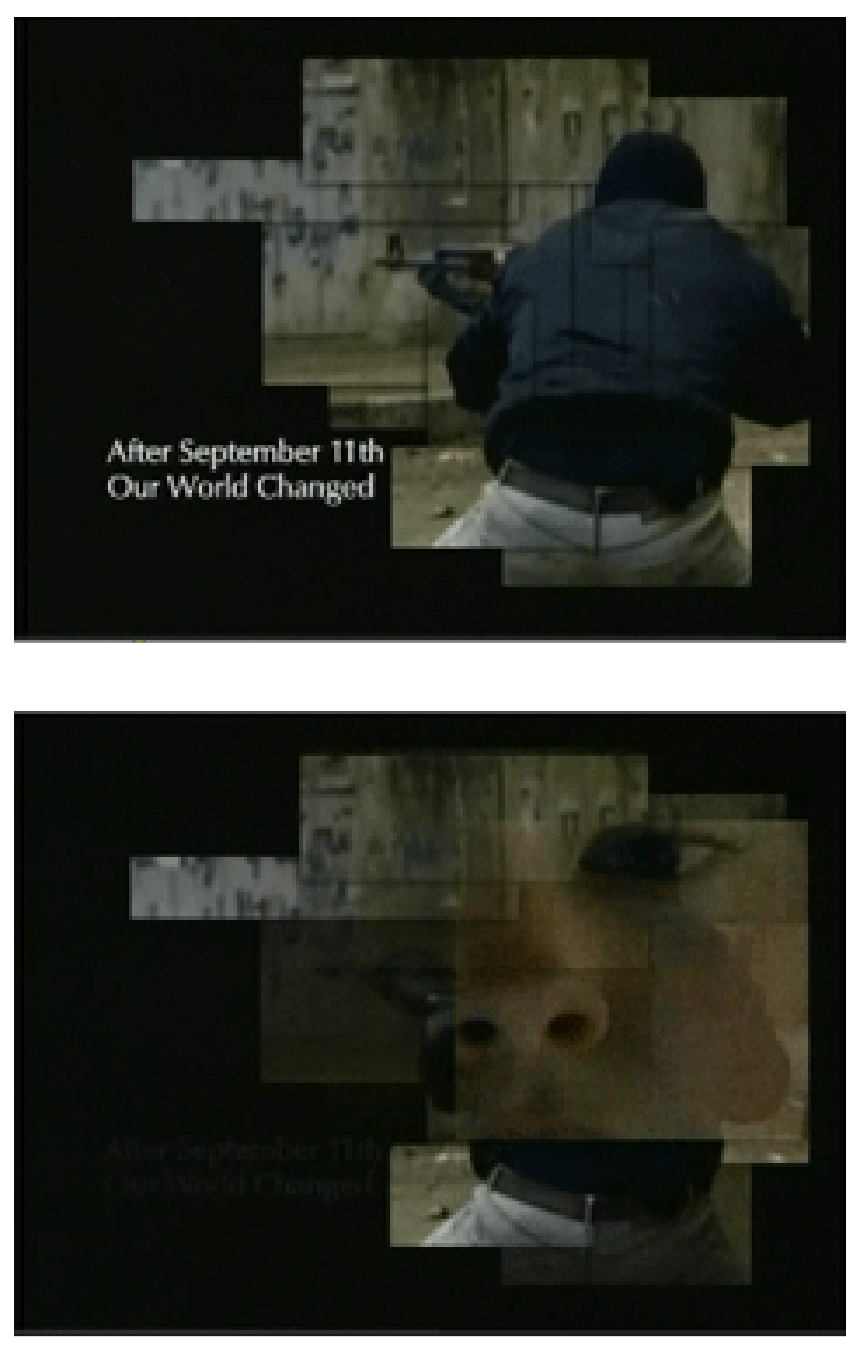

The terrorist image fades into that of the face of a young child. The haunting musical score builds in intensity as the camera zooms in on the child's eye ...

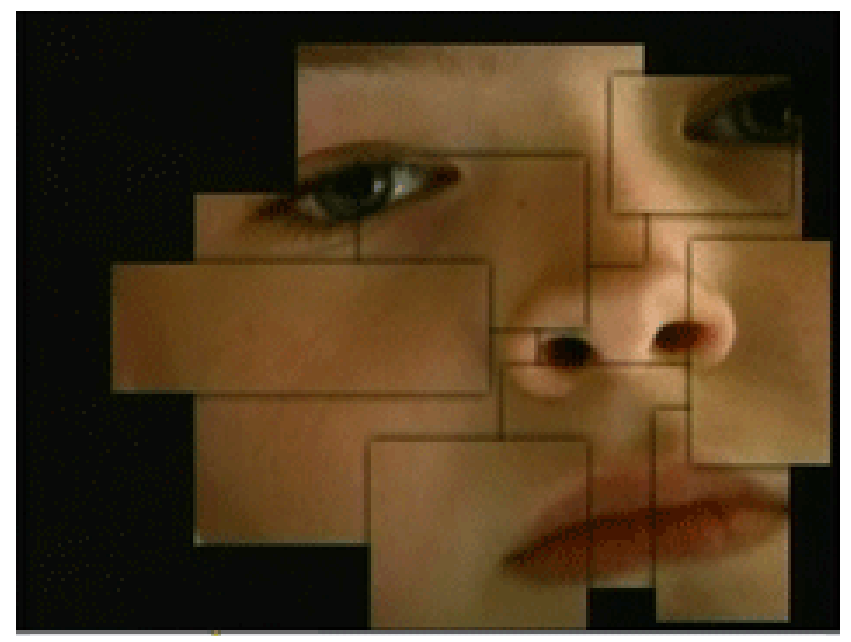




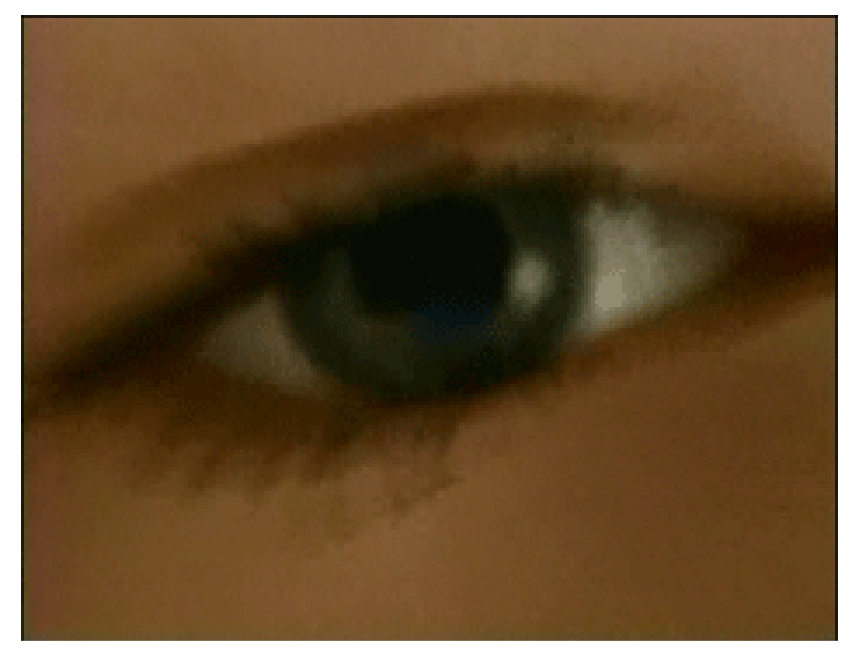

... reaching a climax as the rectangles and boxes disappear, the camera zooms in on the eye of the child drawing closer until the child's eye begins to reveal an image that appears to be Ronald Reagan, followed by quickly by a series of military and intelligence images.
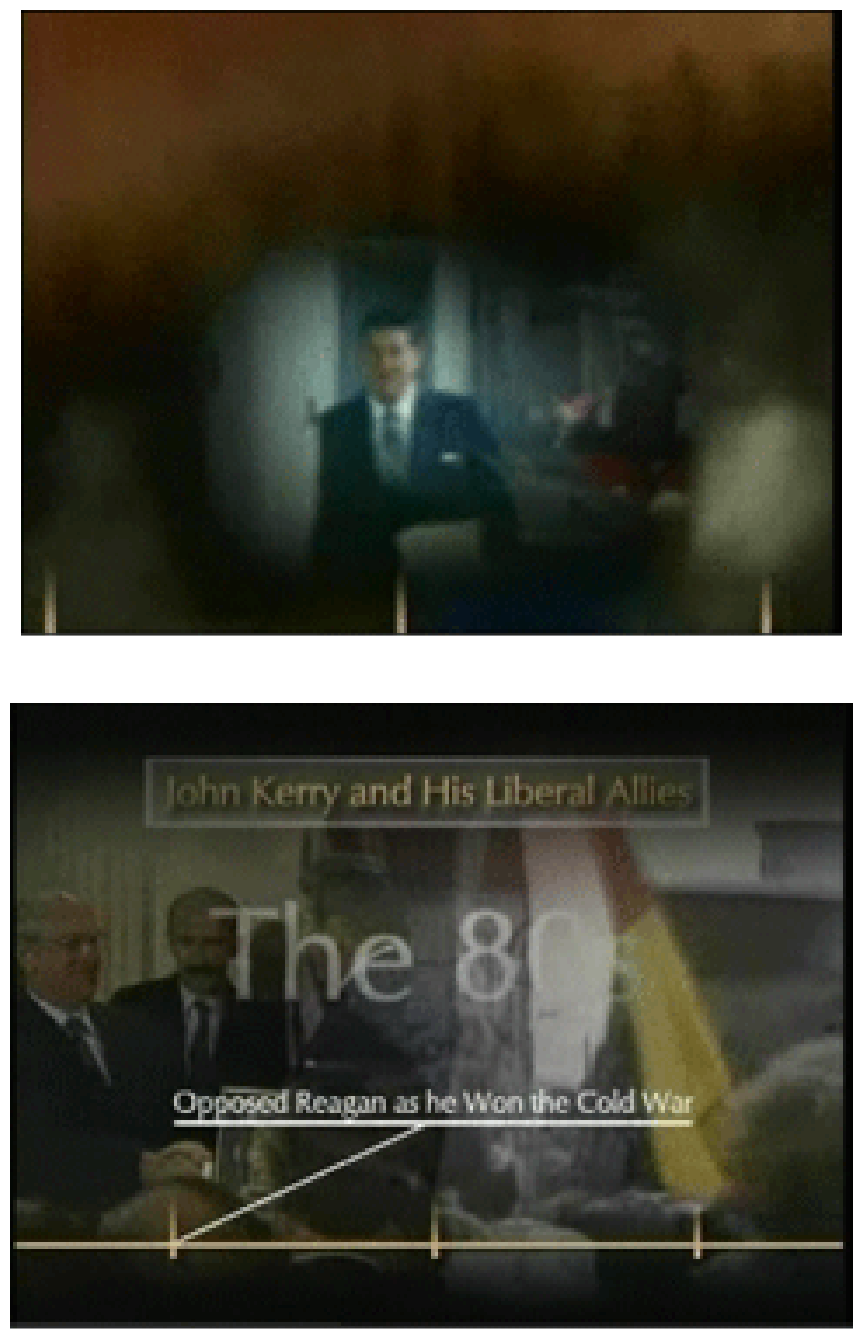

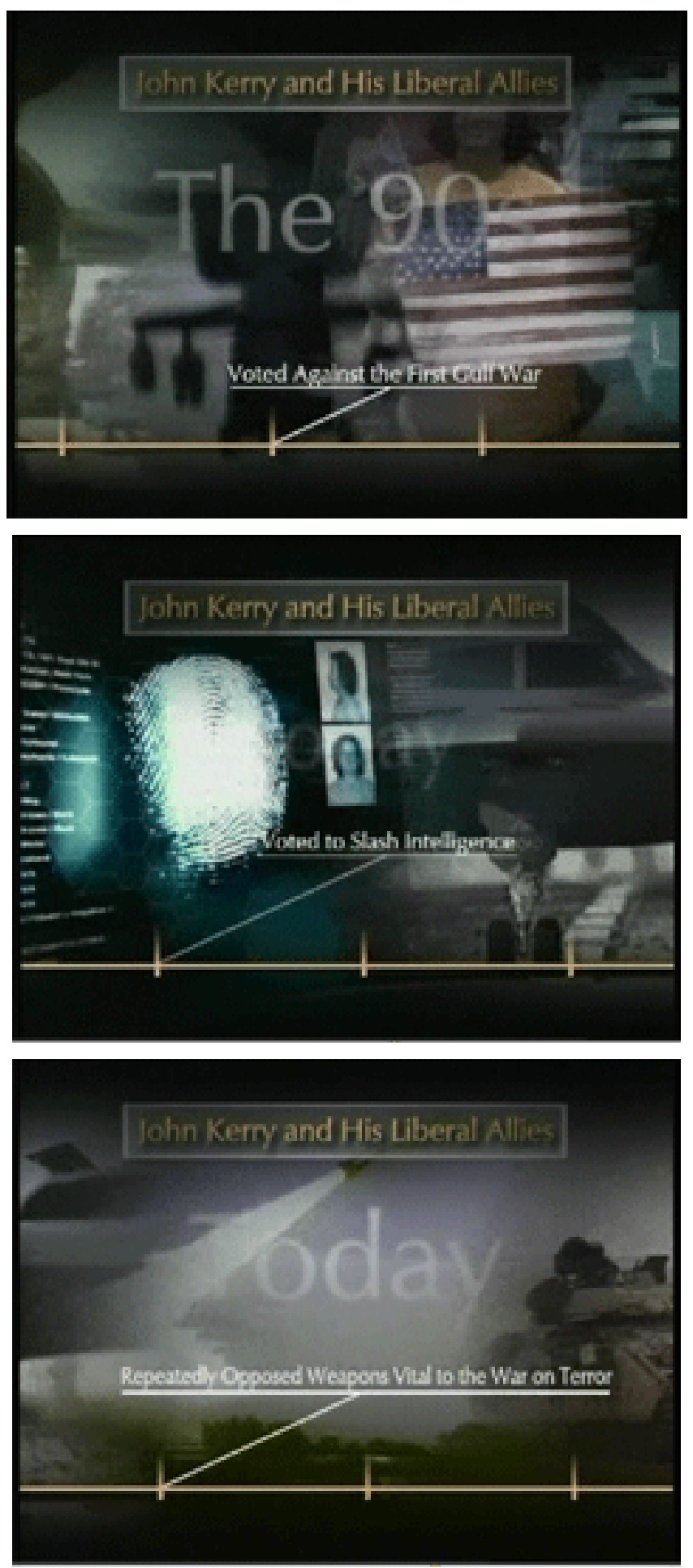


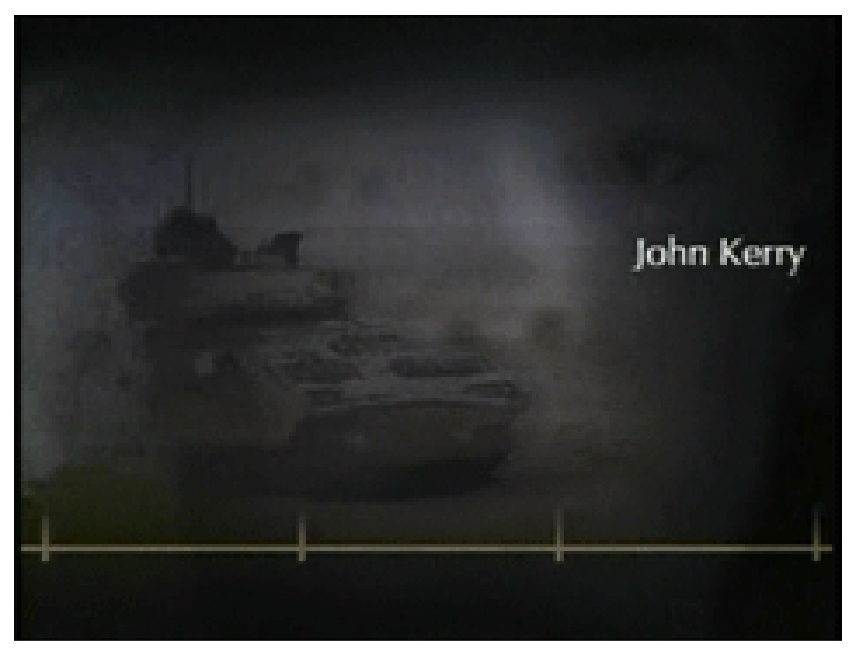

As the timeline fades out, the child's face fades in, along with the text, "John Kerry and His Liberal Allies. Are They a Risk We Can Afford to Take Today?" as the soundtrack draws silent, followed by President Bush reading the ad's disclaimer.

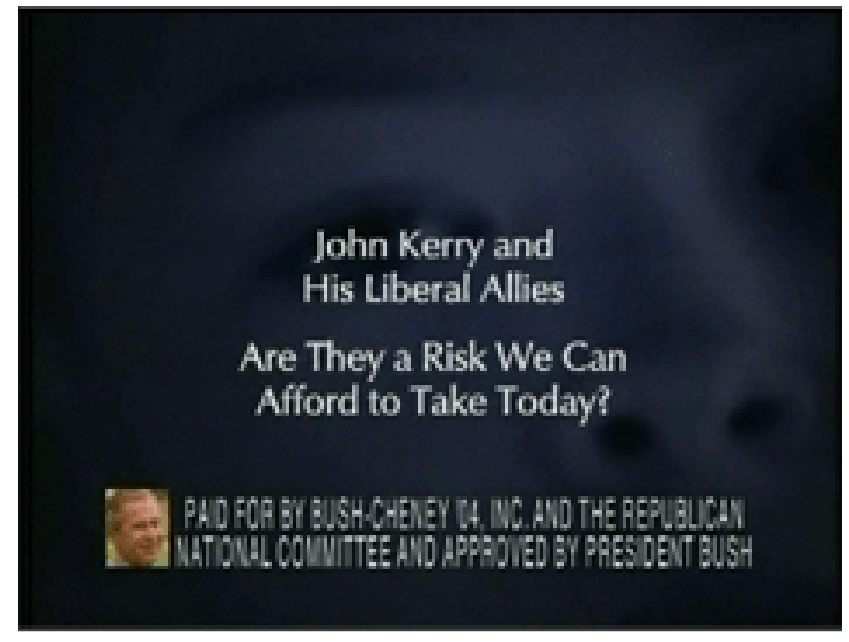

In "Risk," the imagery focuses for the most part on military and intelligence actions in the field, bracketed by the image of the child's eye. In "Peace and Security," the focus shifts to the home front, with scenes of domestic life punctuated by images suggesting the urgency of ticking time, the very essence of the underlying plot line in "24."

\section{BUSH-CHENEY AD: "PEACE AND SECURITY"}

NARRATOR: History's lesson... Strength builds peace... Weakness invites those who would do us harm. Unfortunately, after the first World Trade Center attack, John Kerry and congressional liberals tried to slash six billion dollars from intelligence budgets. And tried to cut or eliminate over 40 weapons now fighting the War on Terror. And refused to support our troops in combat with the latest 
weapons and body armor.

PRESIDENT BUSH: I'm George W. Bush and I approve this message.

(See Associated File \#5 to view)

The ad begins visually and aurally with the hurried ticking of time; episodes of "24" also begin by setting the time and returning to it at each station break. Here, the ever present clock fades in and fades out ...
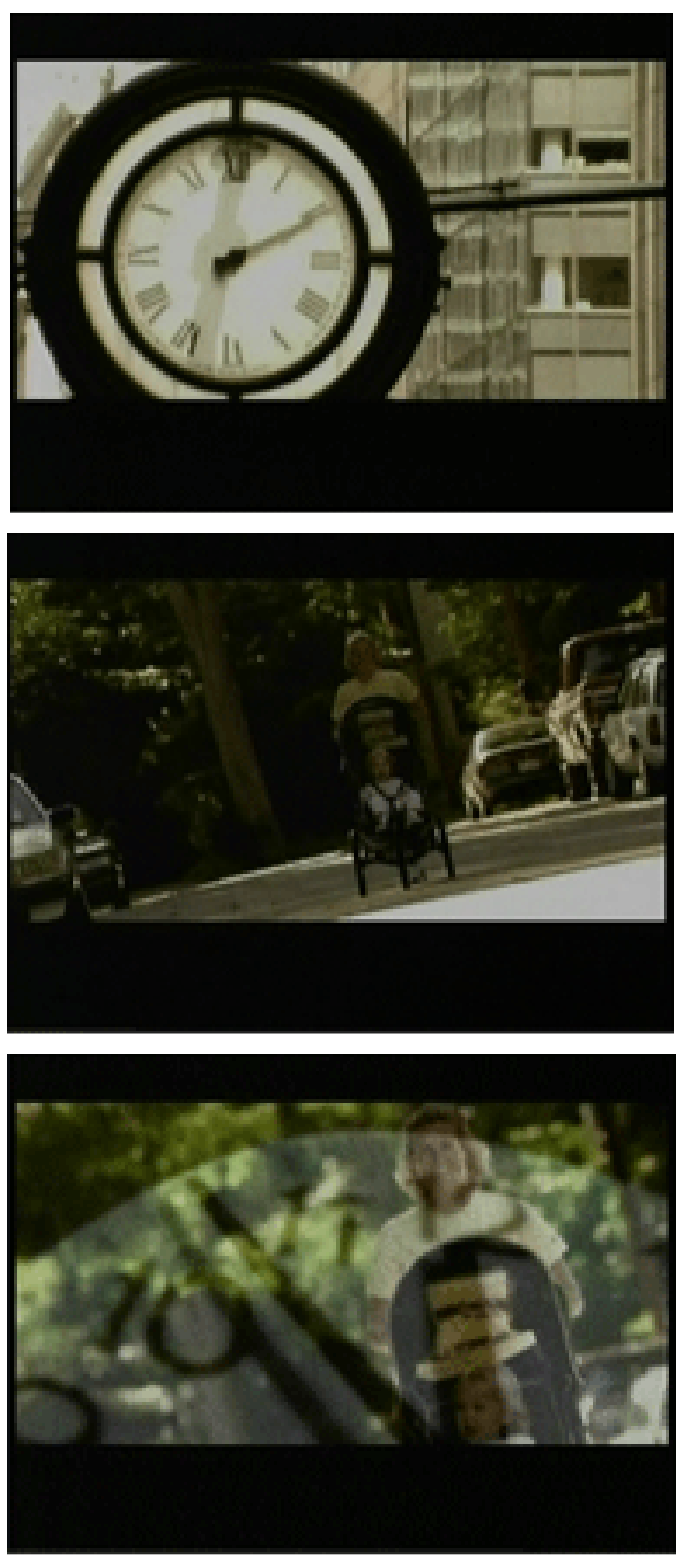
... into a whooping ceiling fan. As the hurried businessman hails a cab before checking his watch, the narrator says Kerry voted to slash intel funds, exaggerating his position and inviting the false inference it happened after 9/11.
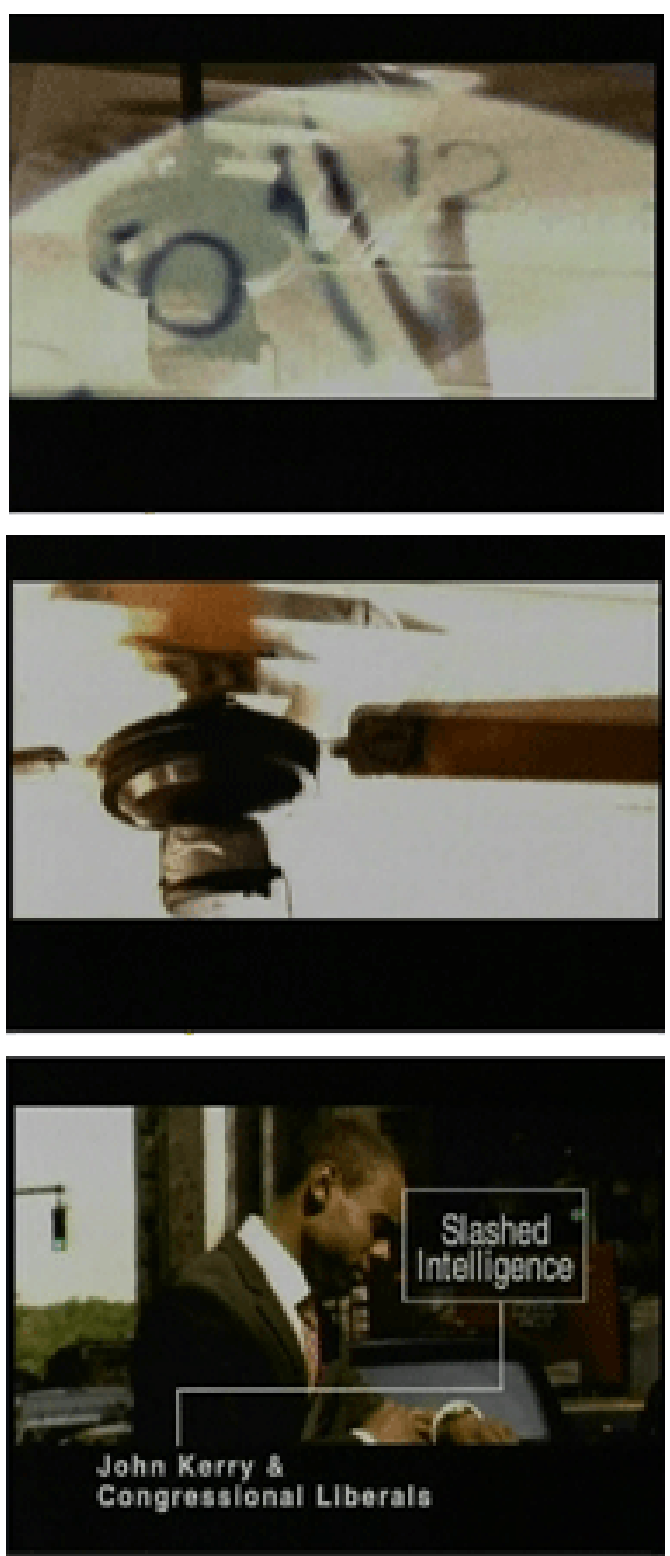
The graphic linkages draw the connection between "Kerry \& Congressional Liberals" providing visually compelling"support" for the claims; the clock ticks throughout, the threat lurking like an unseen time bomb.
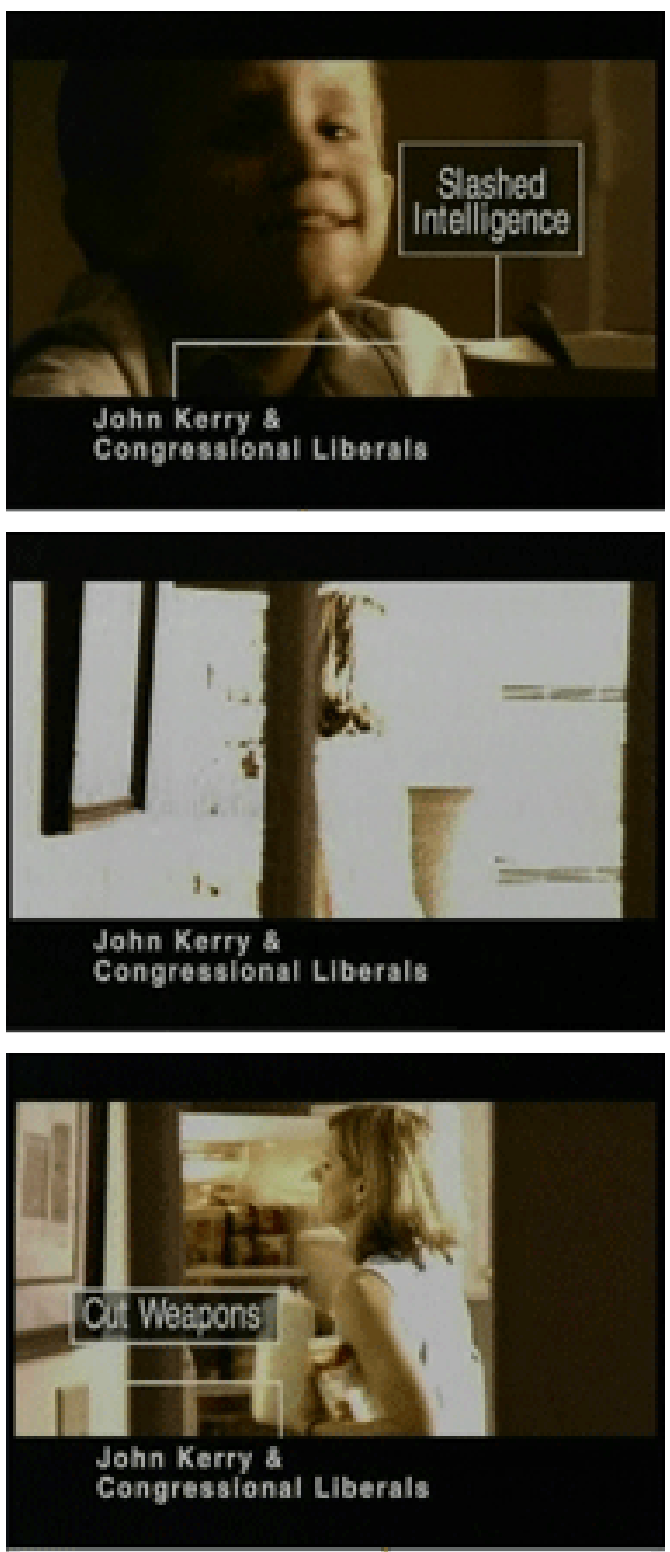
Audio special effects punctuate each charge with short, forceful acuity. A young mother checks her watch, a suburban platoon rolls out ...
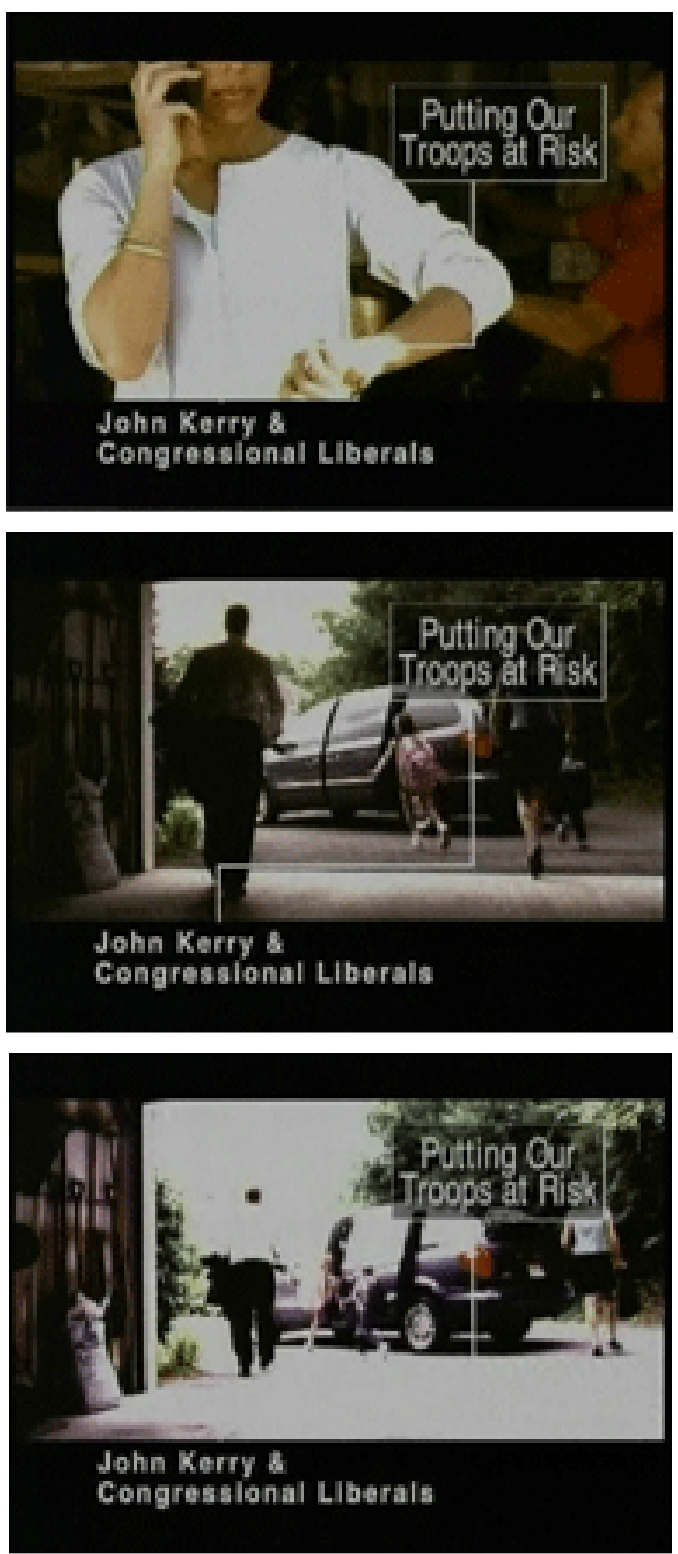
... as a backpack-wearing young girl climbs into the family minivan, the narrator says Kerry "refused to support our troops in combat" and repeats the scurrilous body armor attack. The hands of time tick ever faster, drawing upon midnight as the ad closes.
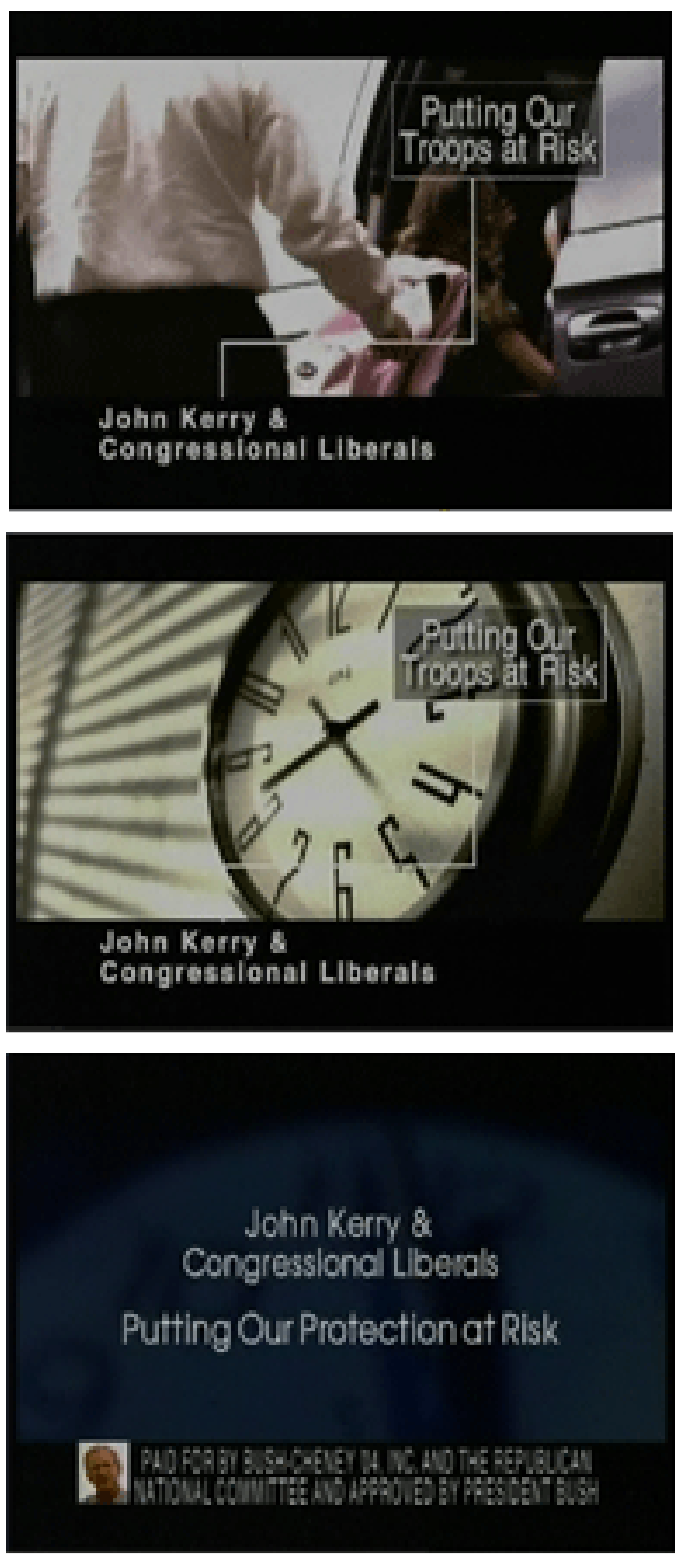
The narrative and imagery are only loosely conjoined logically; but as an audiovisual package, they become one in the minds' of viewers, who fill in the spaces of the gestalt. The alleged sins of Kerry's voting record extend risk from the soldiers in the battlefield to the suburban warriors on the home front. In contrast to "Risk," the aural punctuation of "Peace and Security" has a more domestic ring to it. Crashing cymbals and special effects accompany images of ceiling fans and window blinds rather than attack helicopters and the computers at the counter terrorism center. But the core emotion is the same: an ever-present tense fear. In the 2002 film The Sum of All Fears, the moment when Director of Central Intelligence William Cabot learns that a loose nuke has been delivered to Baltimore, (while he and the president are watching a football game at a stadium in that very city) is dramatized by the camera slowly panning the crowd. The effect is to highlight the ordinariness of the oblivious fans, soon to be visited by the most ominous of horrors. A similar audiovisual dynamic plays out in "Peace and Security."

The Bush ad "Weapons" presented the charge that Kerry opposed various weapons and body armor for the troops in Iraq through images of soldiers in the desert and fighter jets vanishing.

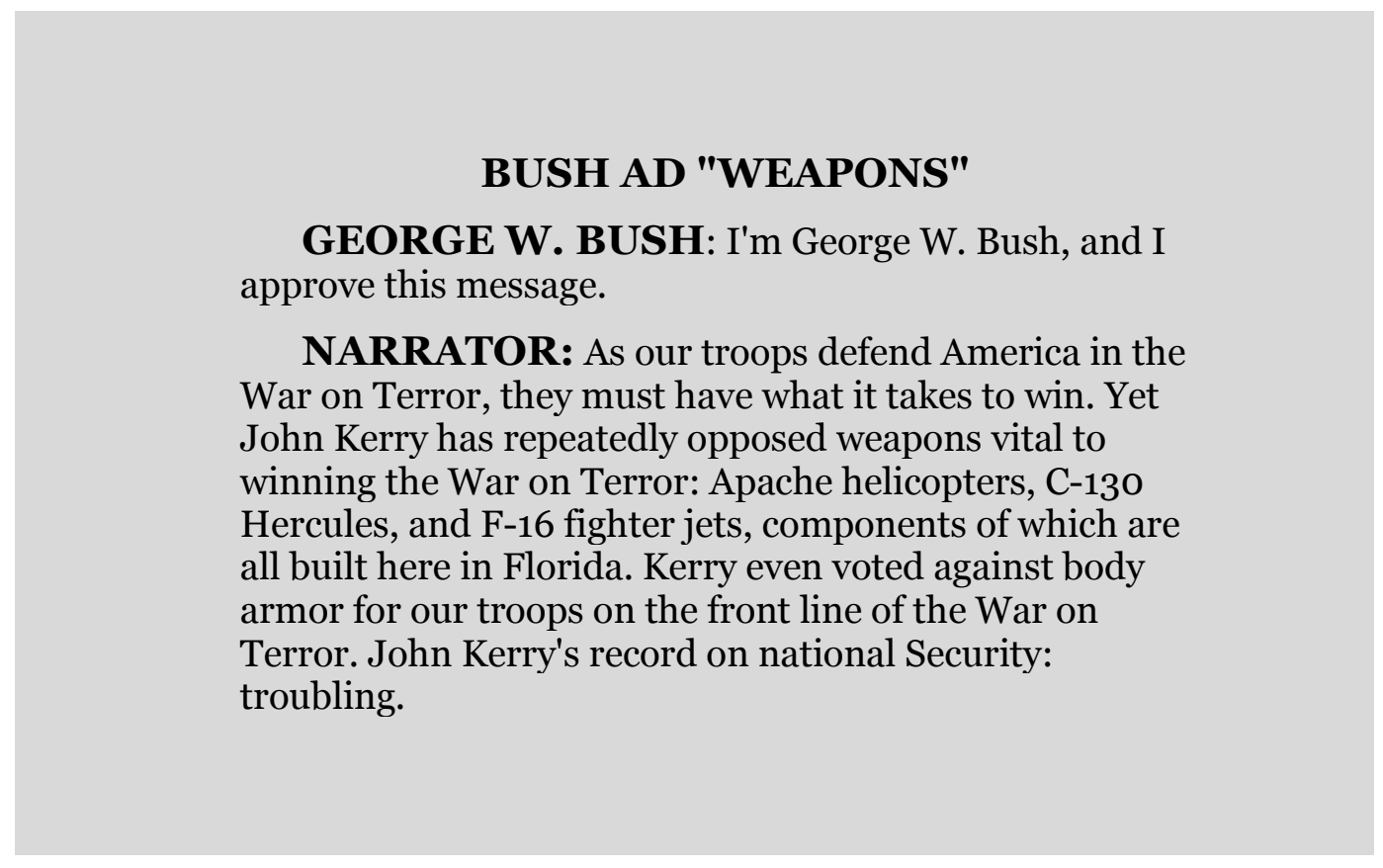




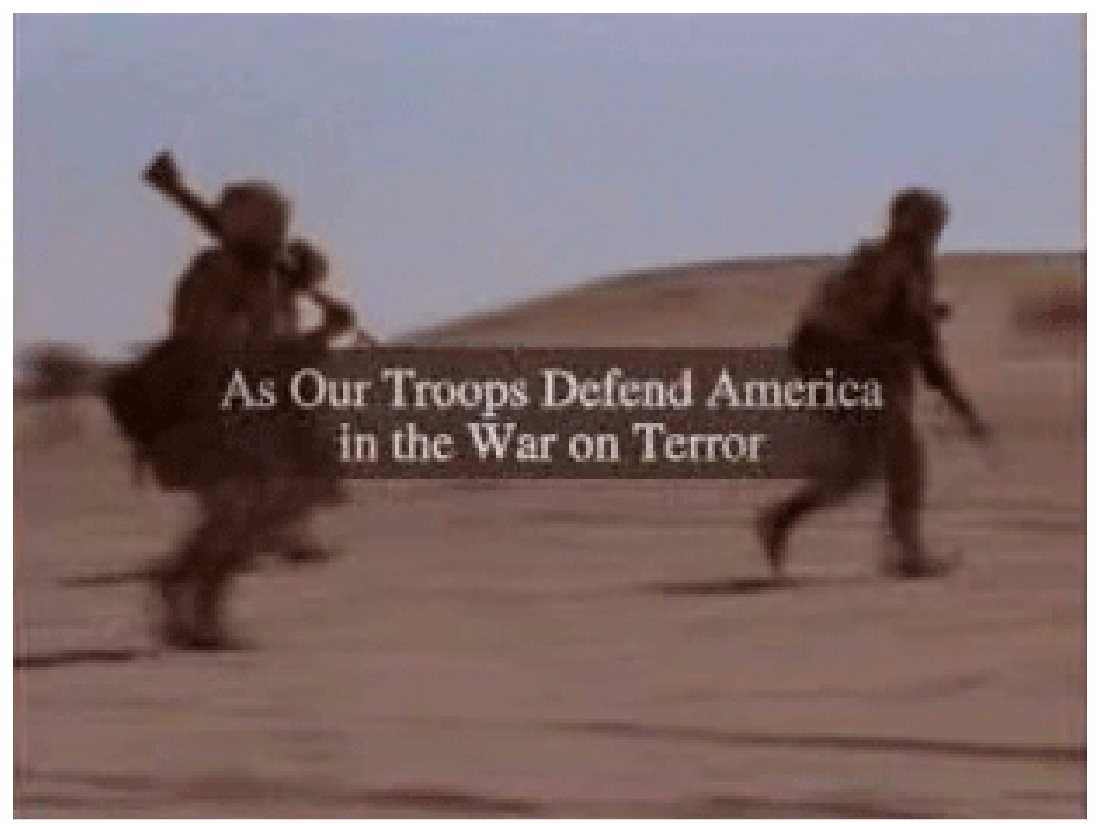

The ad begins by visually opposing our troops defending America and Kerry's opposition to Weapons. Military style drumbeats are heard at the beginning. As the voice over and text on the screen turn to Kerry, a bell chime sounds, and the troops begin to move in slow motion as the soundtrack turns more ominous.

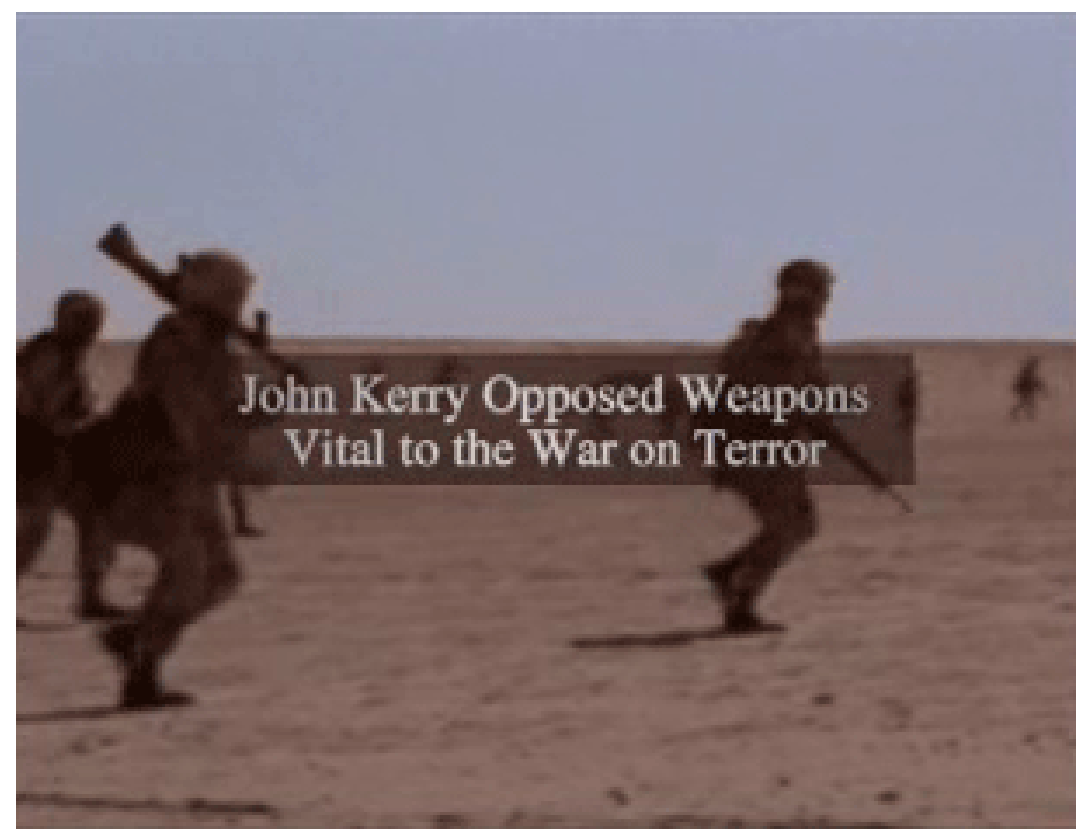




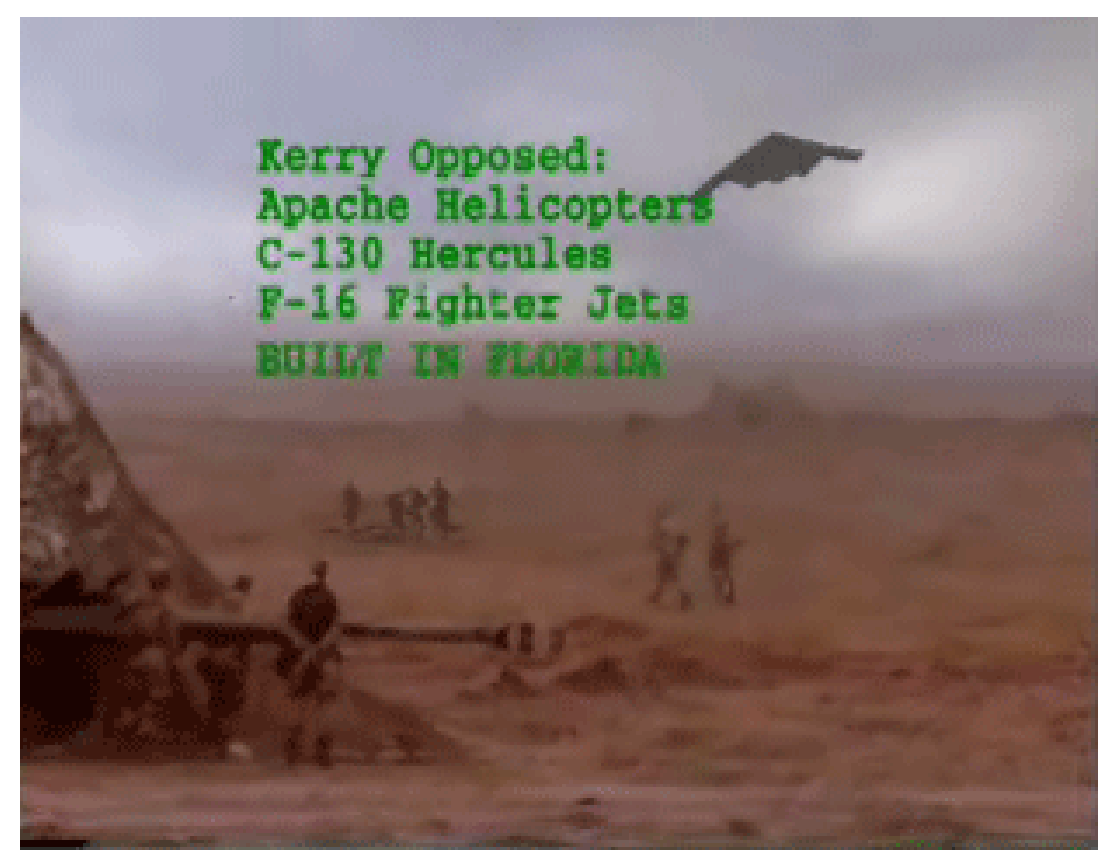

As the ad charges Kerry with opposition to specific weapons, a jet swoops in (left) only to be engulfed in the dark clouds symbolizing the threat posed by Kerry. Frightening sound effects mark each charge against Kerry.

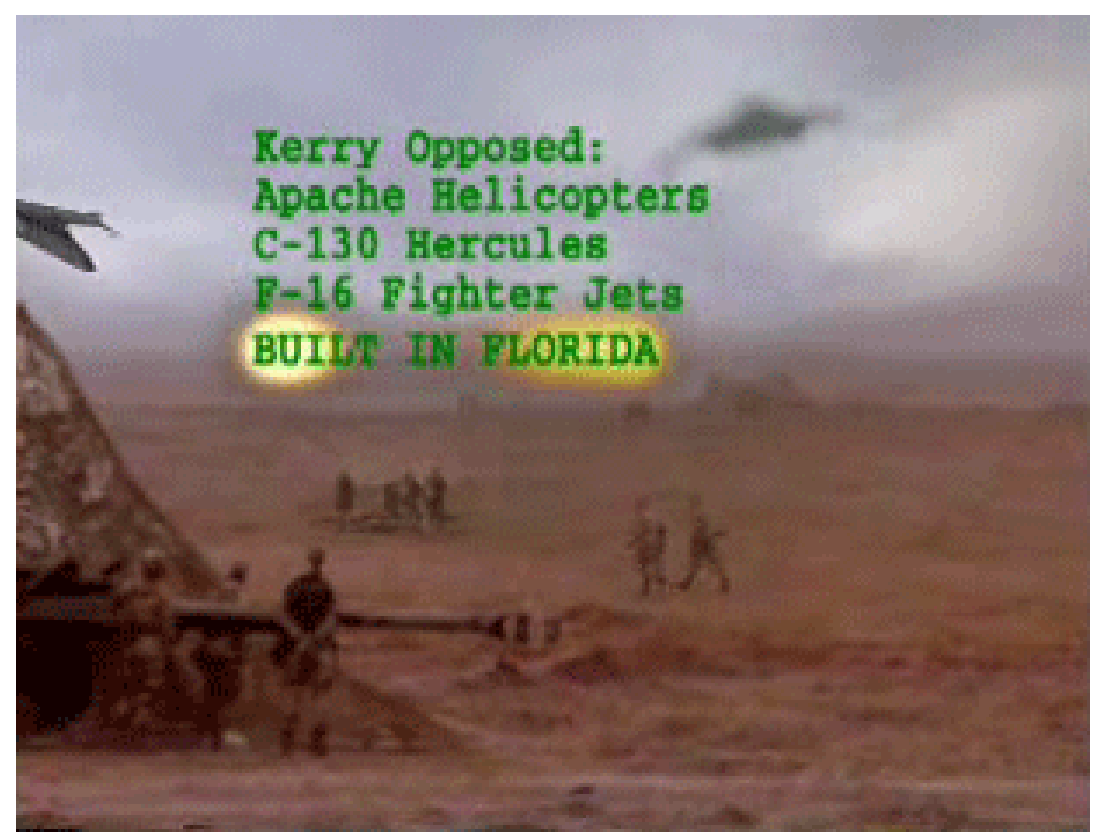

The plane continues to fade out as two others appear on the left of the screen. As "built in Florida" is highlighted, soon all the planes have disappeared, leaving the troops without the weapons (presumably the ones Kerry opposed). 

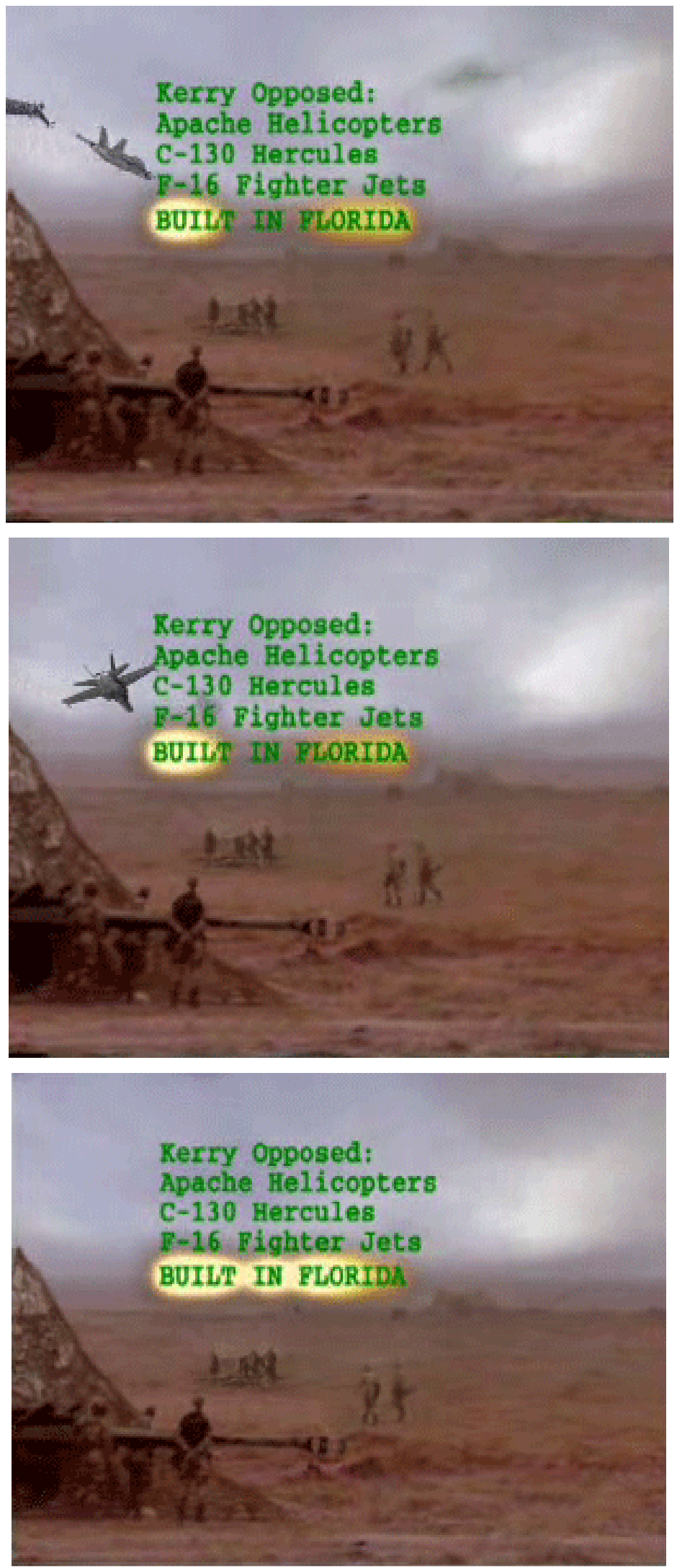

Stripped of fighter jets, helicopters, and troop transport planes, 
the desert encampment stands alone as the superimposed text and narration level the vicious attack that Kerry opposed body armor, followed by a second bell chime. The sound effects suggest a windstorm or even tornado as the ominous clouds continue to roll across the landscape. A lone soldier looks in the direction of the others off in the distance as the dark cloud threatens them. Then he looks toward the screen as if to appeal to the viewer to support the troops by opposing Kerry.

"Weapons" began airing early in the campaign. In the final days of the campaign, the ad "Whatever It Takes" began to air. It is a stirring response to the most searing indictment of Michael Moore's Fahrenheit 9/11, the suggestion that Bush was oblivious or uncaring about the human costs of the Iraq War. The ad is based on a section of Bush's acceptance speech at the Republican Convention in New York. His words are solemn and inspirational. The ad interposed imagery of audiences of soldiers and veterans, including an image of a particular soldier that had been edited into the same crowd scene more than once, providing minor embarrassment for the campaign after it was initially exposed by a posting on the liberal weblog DailyKos (Rutenberg 2004). The ad ends in with an emotional crescendo and a frenzy of flag waving enthusiasm.

\section{BUSH AD "WHATEVER IT TAKES"}

PRESIDENT BUSH: These four years have brought moments I could not foresee and will not forget. I've learned first hand that ordering Americans into battle is the hardest decision, even when it is right. I have returned the salute of wounded soldiers who say they were just doing their job. I've held the children of the fallen who are told their dad or mom is a hero but would rather just have their mom or dad. I've met with the parents and wives and husbands who have received a folded flag. And in those military families, I have seen the character of a great nation. Because of your service and sacrifice, we are defeating the terrorists where they live and plan and you're making America safer. I will never relent in defending America, whatever it takes. (voiceover): I'm George W. Bush and I approved this message.

Bush is doing that which only the president can. The "set" at the convention featured a gigantic presidential seal, and "Whatever It Takes" invokes the full range of the office, both as commander-in-chief and Chief of State, while deploying a full palette of audiovisual evocations of leadership. Bush not only orders troops into battle, he returns the salutes 
of wounded soldiers and he's there when the aggrieved receive the "folded flag." The ad's uplifting musical score emphasizes what, in Bush's convention speech, was already an emotionally moving moment. Visuals show rapt interest in viewers looking "up" at the president. It was the high point of the speech, and serves as an emotional high note for the campaign. The ad concludes with the tag line, "whatever it takes." The very essence of the Bush campaign was devoted to the notion that this is literally the case, and that, implicitly, John Kerry will not do "whatever it takes" to defend America. While Kerry's character is portrayed as questionable unto despicable, Bush's character becomes one with the character of the military families, "the character of a great nation."

The twin Bush messages that John Kerry is an unreliable foe to terror and that the terror threat is frightening are manifest in the ad "Searching," and especially in its use of visual transitions to punctuate each clip in the ad. According to Factcheck.org, "(t)his ad is the most egregious example so far in the 2004 campaign of using edited quotes in a way that changes their meaning and misleads voters"

(http://www.factcheck.org/article269.html). If "Whatever It Takes" is designed to define Bush's character, "Searching" is the Bush's campaign's attempt to define John Kerry's character, narratively and audiovisually.

The ad begins with a disclaimer featuring colorful images of the president and his wife, then turns dark. Better the ad's sponsor be seen smiling before the horror show than after.
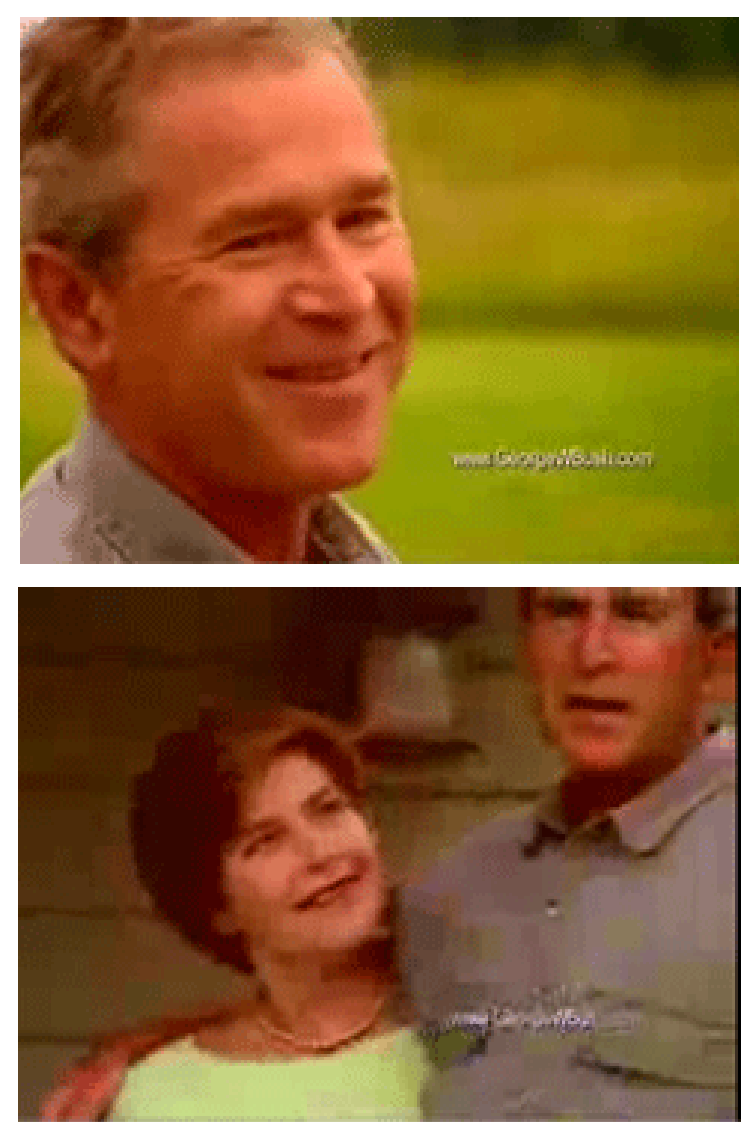
John Kerry on

the War on Terror 
PRESIDENT BUSH: I'm George W. Bush and I approve this message.
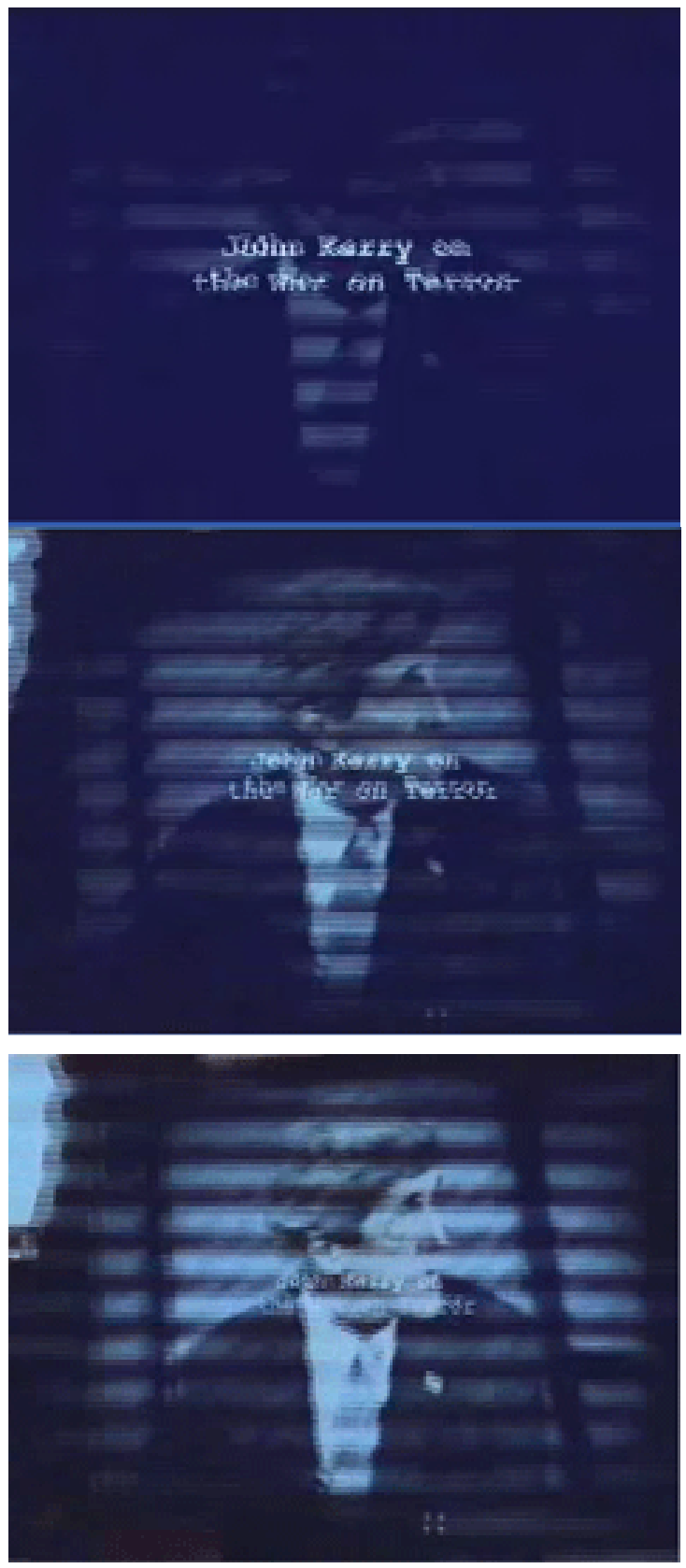


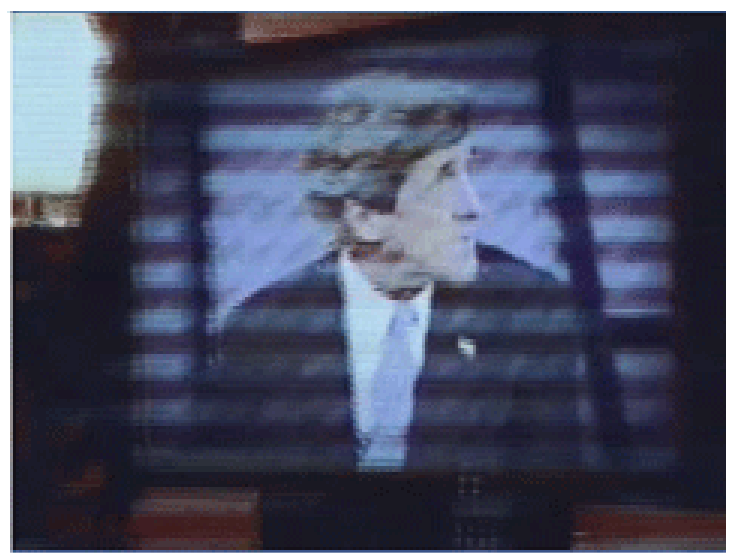

SENATOR KERRY: It was the right decision to disarm Saddam Hussein, and when the President made the decision I supported him.

The ad uses attenuated visual punctuation, superimposing vertical bars across the image fading in of Kerry on a TV. The bars are like those in the Bush-Cheney 2000 ad "Really?" but appear harsher and more foreboding. The depiction of Kerry on TV follows the pattern established by Bush advertising in 2000 which invariably portrayed Vice President Al Gore "on TV", usually canted, just as in the ad watch format developed by Jamieson to highlight the questionable claims in ads without allowing the ad to appear "as news" (Richardson 2002).

In this ad, a tense, ominous piano theme develops, joined by an eerie, solemn counterpoint melody evoking horror and threat. They reach a crescendo at the end of the ad, accompanied by the electronic slashing of the guillotine sound effect (oft heard in political advertising) following Kerry being shown saying "I actually did vote for the $\$ 87$ billion dollars before I voted against it."

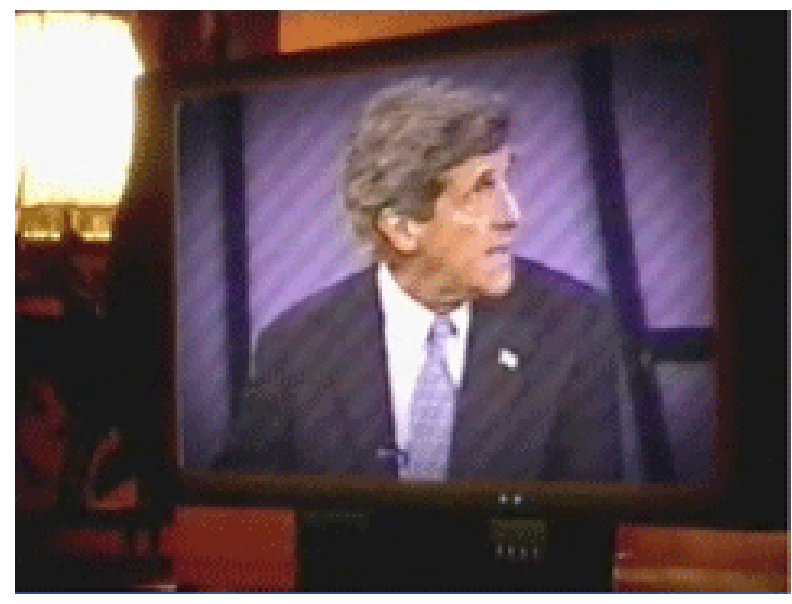



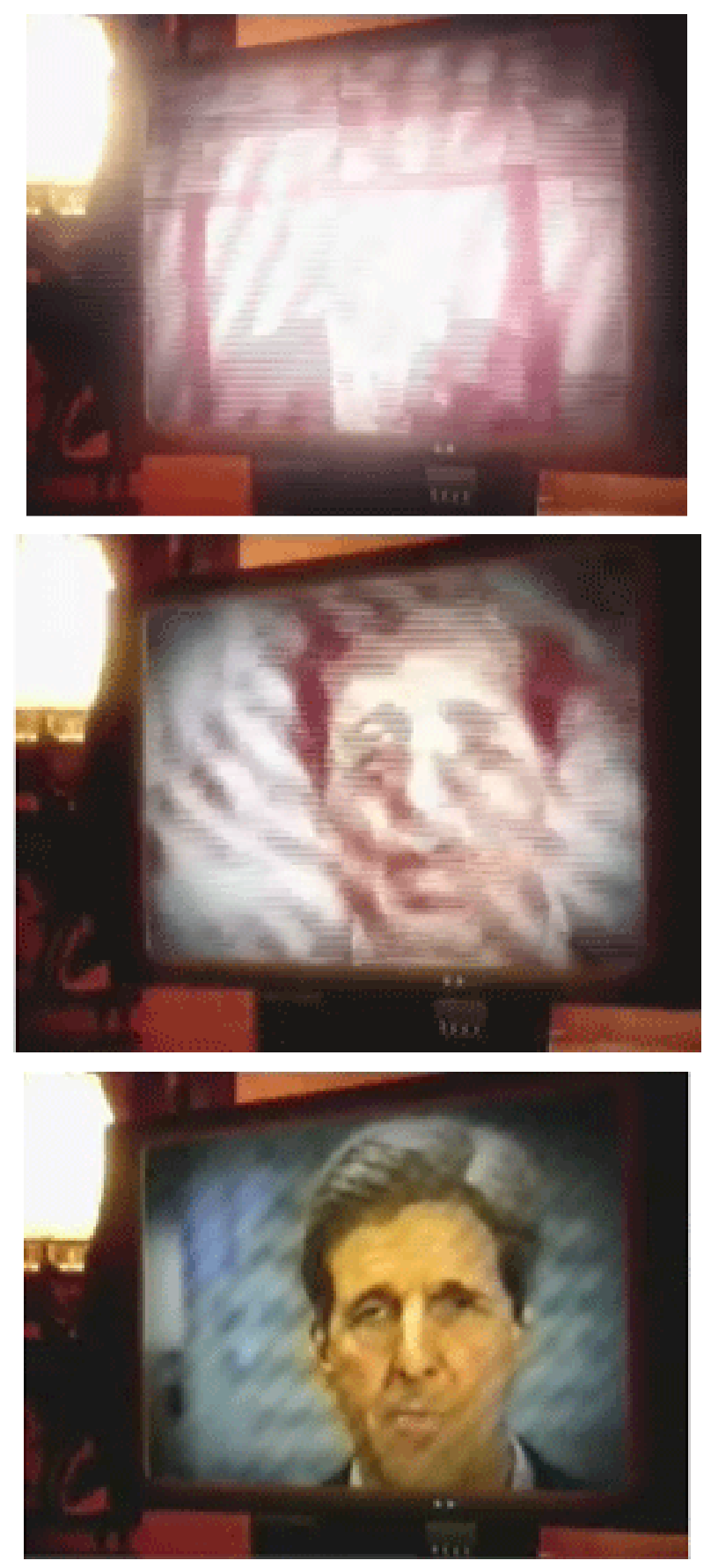

Subsequent visual punctuation turns downright radioactive, with Kerry's TV image glowing brightly, then becoming clearer, though not clear.

SENATOR KERRY: The winning of the war was brilliant. 


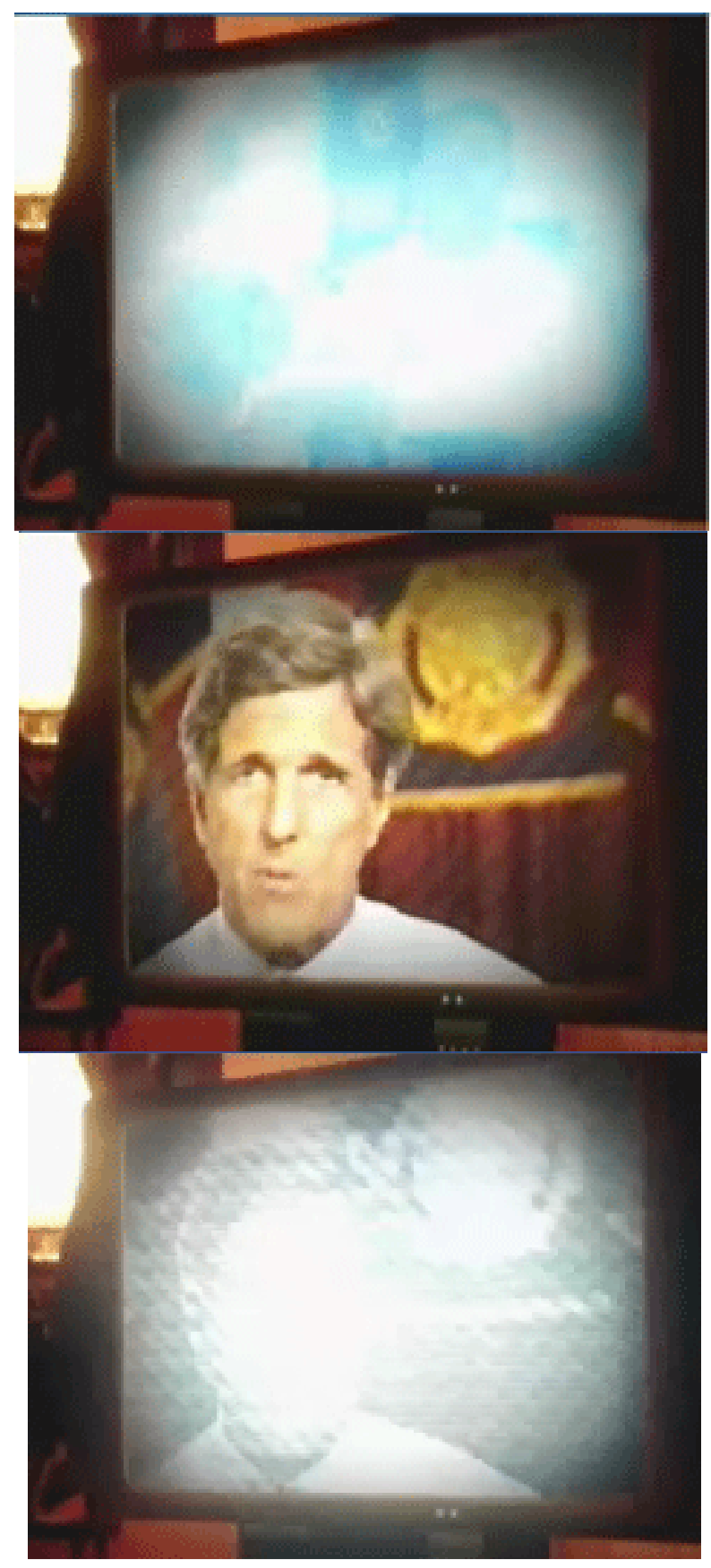




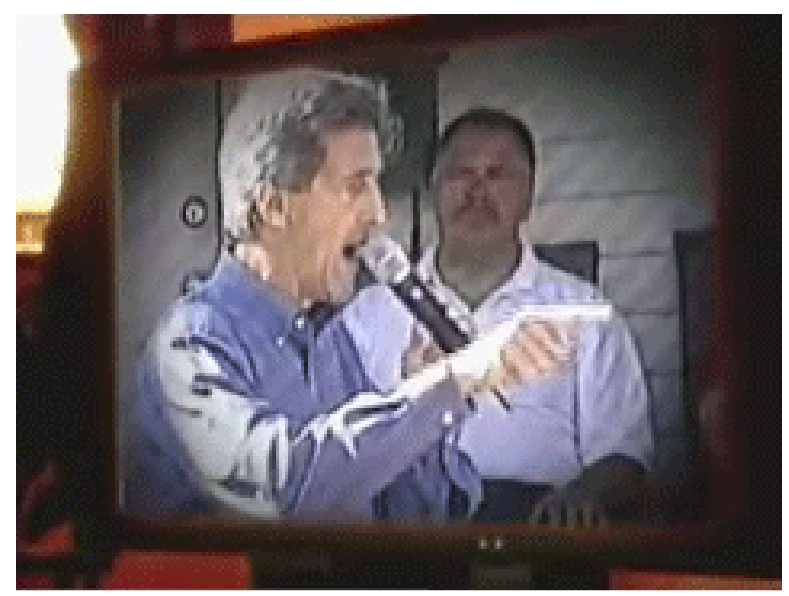

SENATOR KERRY: I don't believe the President took us to war as he should have.

Additional violent transitions mark the separation of different clips from the Massachusetts Senator.

SENATOR KERRY: It's the wrong war, in the wrong place, at the wrong time.
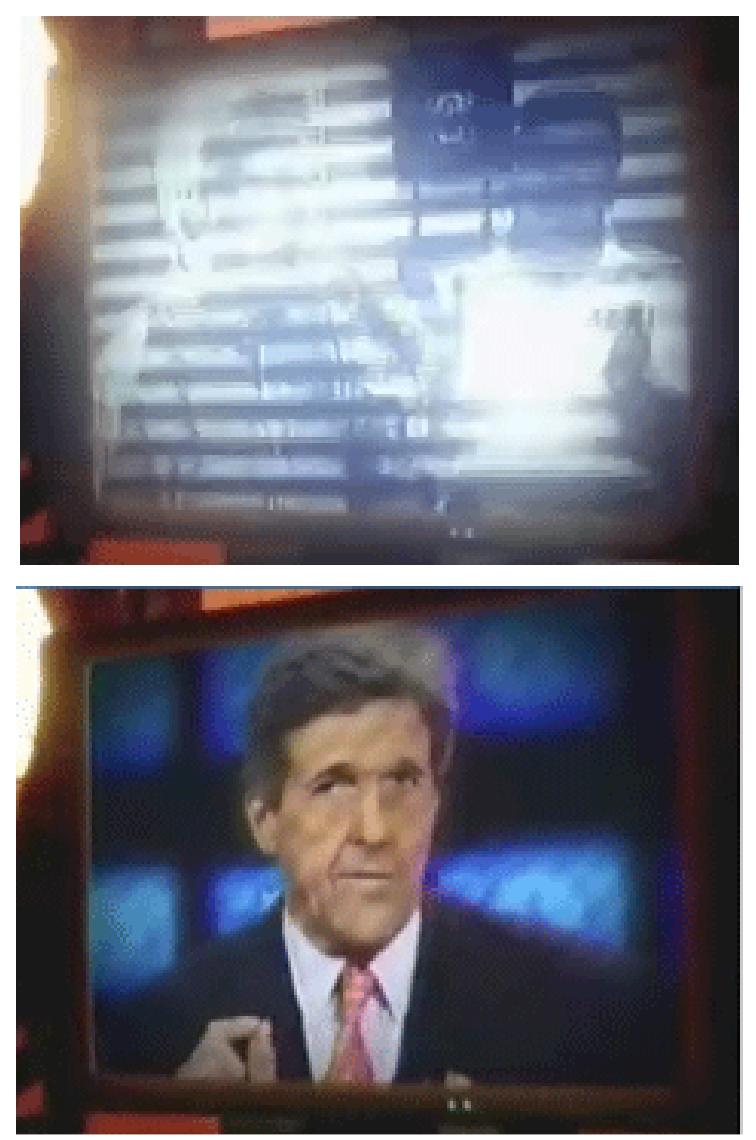


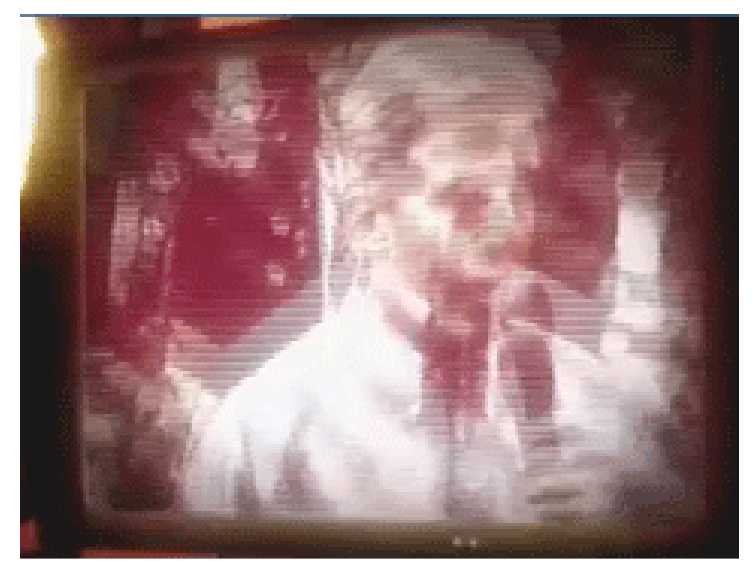

SENATOR KERRY: I have always said we may yet even find weapons of mass destruction.

The ad images take the use of unflattering images of the opponent to new heights, combining vertical bars and the sudden dramatic shift in lighting that suggests a photographic negative.

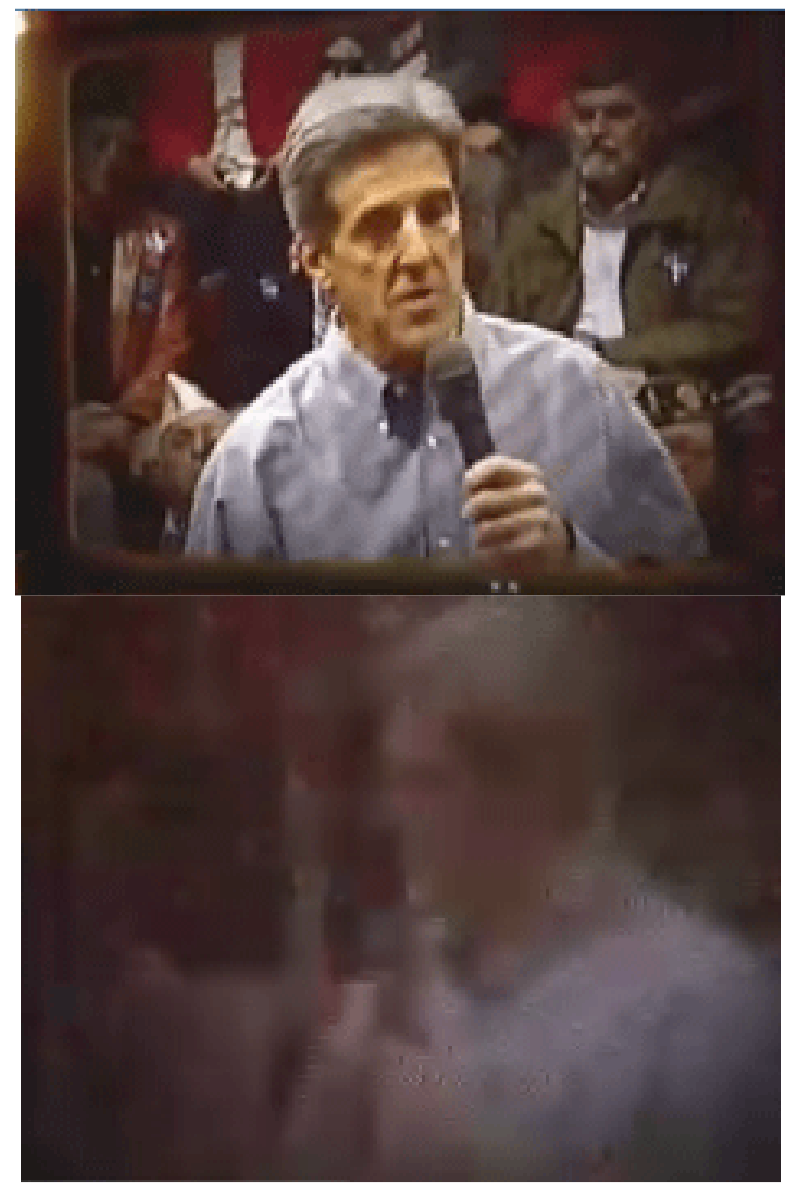




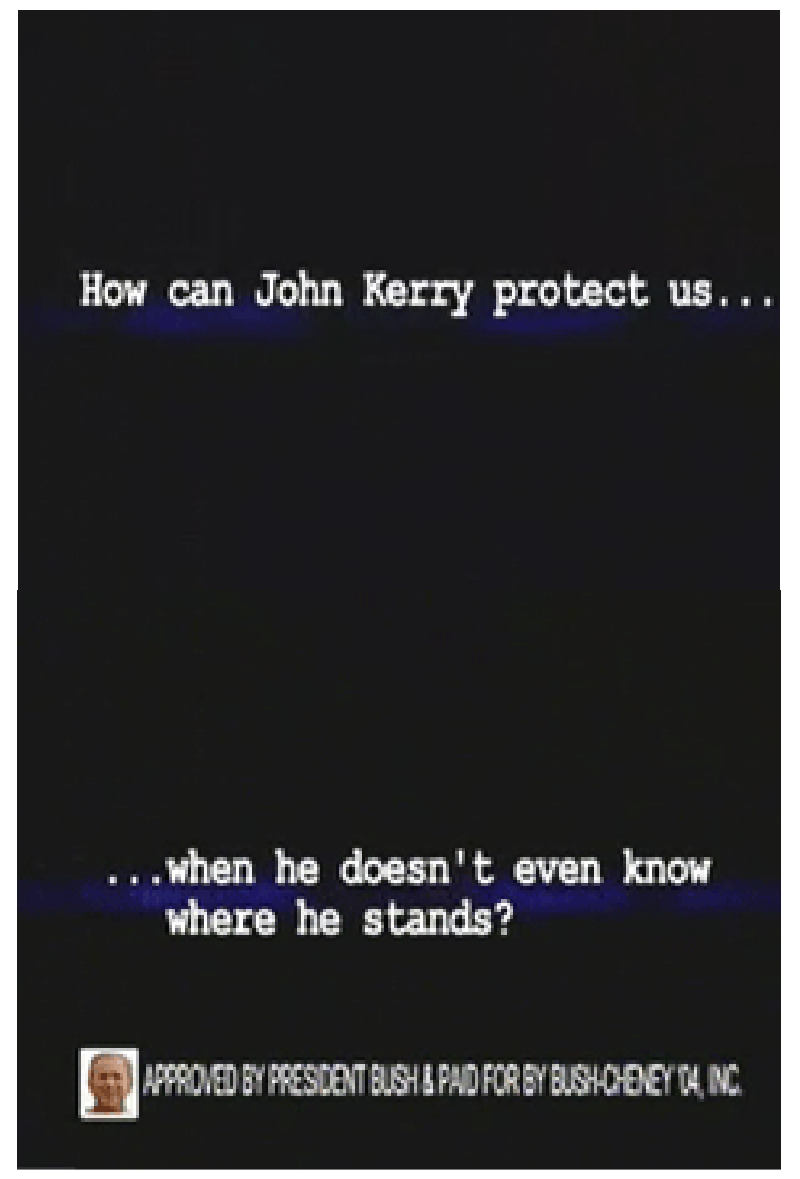

The Kerry statements quoted by Bush in fact are perfectly consistent, especially when taken in context. Kerry voted to authorize force against Iraq (while hoping Bush would use the vote as a bargaining chip rather than green light); he praised the way the military conducted the first phase of the war and consistently argued that Bush went about the war the wrong way by not allowing more time for diplomacy and by failing to secure a broad coalition of allied support. The subtlety of Kerry's positioning is ransacked first by the narrative distortions of the ad, and then more forcefully by the searing video attack. The video portrays Kerry in a monstrous light that would be implausible even in a Bush-Cheney ad if attempted with word alone. The evocative imagery relies on viewers to fill in the horrifying details on their own; the ad provides the match to the preexisting kindling of audiovisual associations in viewers. Through the Bush ads, the question ceases to be the consistency of Kerry's character, instead becoming the characterization of Kerry's consistency.

Recognizing that campaign ads draw upon popular culture to convey the emotional substance of their persuasive appeal is one thing; effectively countering such evocation is quite another. One could argue that if the appeal or characterization itself is grounded in the unarticulated premises drawn from the audiovisual and narrative conventions of popular entertainment, so too must be the counter appeal or counter-characterization. The first step would be to recognize the cultural referents, then name them. Once identified, counter 
characterizations can be offered in context. Here, for example, if George Bush is suggesting to viewers that he is the Jack Bauer of the real "war on terror," then perhaps the most effective counter characterizations that have to be made are those pointing to the flaws in the Bauer approach. Rather than attempting to argue the specific merits of this or that surveillance or interrogation technique of the Bush administration, which may fail to sustain the attention of many voters, the more fundamental task may be to document why Jack Bauer's approach to fighting terror is ultimately flawed.

The parallel between Bauer and Republicans and the Bush administration has not gone unnoticed. New York Times editorialist Maureen Dowd wrote that "(i)f the Democrats are like the dithering 'Desperate Housewives,' the Republicans have come across like the counter terrorism agent Jack Bauer on '24': fast with a gun, loose with the law, willing to torture in the name of protecting the nation. Except Jack Bauer is competent" (Dowd 2006). From the right, Patrick Buchanan has referred to Bush as our "Jack Bauer in the war on terror," and writers for the conservative American Spectator and Washington Times have made the linkage as well (Orr 2006). In a piece on the politics of "24" in The New Republic, Christopher Orr describes the series (which he sees the defining TV show of the era) in a way that echoes the fabric of the Bush ads described above:

Now wrapping up its fifth season, the show plays like a breakneck rundown of Richard Clarke's apocalyptic nightmares: loose nukes, weaponized viruses, nerve gas attacks, assassination attempts, government conspiracies, terrorist cells and subcells. For those not yet on the edge of their seats, the urgency of these threats is further upped by "24"'s signature gimmick: The show takes place in "real time," with each episode constituting one hour--complete with ticking clock bracketing commercial breaks--and each season adding up to a single, frenzied, 24hour day (Orr 2006).

It is possible, then, that one might be more effective in engaging the central issues in confronting terrorism by confronting Jack Bauer than by confronting George Bush. Orr, for example, notes that, "the contours of Bauer's character have far less to do with the demands of geopolitics than with the demands of genre. Bauer is not a hero because he does whatever is necessary; whatever he does is necessary because he is the hero" (Orr 2006). Bauer is right when he uses any means necessary; so too is he right when he chooses a more humane approach. Orr also points to the simultaneously maddening and endearing tendency of Agent Bauer to put the nation at risk, jeopardizing national security as he applies his whatever it takes mentality to protecting his family. George Lakoff has argued that the fundamental difference between liberals and conservatives is that, while both use the metaphor of the nation as a family (with political leaders as the parents and citizens as the children) to reason through the otherwise daunting complexities of politics, conservatives embrace a strict-father morality while liberals value a more nurturant-parent morality (Lakoff 1996). Lakoff's work pre-dates the September 11 attacks, and the implications of his approach for such issues are not completely obvious. Yet, if in fact he is right about the differences 
between liberals and conservatives, the Bauer case offers a potentially clarifying template. In Bauer's private-before-public morality, the issue becomes joined in a vivid, accessible way. The very characteristics that initially appear strong may in fact be weak; the issue of whether there is a larger "we," beyond the family or tribe, to which Americans owe allegiance can be brought to the fore. It can be done, moreover, in a way that engages ordinary Americans without becoming bogged down in wonkspeak.

Orr concludes his analysis by suggesting that the politics of "24" are far more ambiguous than conservatives fathom, and not entirely inspiring:

"24" is, in some ways, the perfect cultural artifact for this postSeptember 11 moment. It extols patriotism but doesn't quite believe in it, preaches a self-sacrifice it practices only intermittently, and offers up a world in which the choices are always impossible but the answers are always right. On the surface, it flatters our belief that we're better now, more stoic and unselfish, committed to ideals larger than our individual wants and needs. But, below, it reassures us that it's OK to place our own households first, that politics is empty if not actively corrupt, and that belief in a cause will only lead to disillusion or betrayal (Orr 2006).

The move to engage fact through fiction is not as far-fetched as it sounds. Former counter terrorism chief Richard Clarke explained why he turned to fiction writing to convey his fact-based concerns about future terrorist threats in an article written for the Atlantic Monthly (Clarke 2005): "(i)n both the Clinton and Bush administrations, the only time I was really effective in getting senior officers to pay attention was when I had tabletop war games ... (t)hat did more than any briefing paper I might write" (Rich 2005). Clark told interviewer Frank Rich of the New York Times that "(p)op culture is frequently ahead of where the news media are on these things." Clarke noted that while in 2002, then national security advisor to President Bush Condoleeza Rice said "I don't think anybody could have predicted that these people would take an airplane and slam it into the World Trade Center," in 1994 Tom Clancy's novel Debt of Honor involved a 747 crashing into the Capitol during a Joint Session of Congress at the hand of a Japanese pilot, and the 1996 movie "Executive Decision" featured Islamic terrorists who had seized control of another 747 so they could detonate a biological weapon in the nation's capital. (Investigations have shown that actual threat reports within the U.S. government did predict the airplanes as missiles scenario repeatedly before September 11, including one threat specifically targeted the World Trade Center in 1998) (Rich 2005).

In essence, then, the question raised by the Bush-Bauer link may be whether America really needs a president modeled after a "super patriot with ADD" (Sternbergh 2006).

Engaging the politics of "24" also invites analysts to reverse the flow of inference. If "24" helps explain how Bush-Cheney campaign ads work, does it also tell us something about the Americans who make up the 
audience for those ads? The award-winning British journalist Johann Hari describes Bauer as a "torturing hero," and laments the "lurch in post-9/11 American culture towards the sympathetic, no, glorified, depiction of torture" (Hari 2006). In a review of two books on U.S. torture in Afghanistan and Iraq appearing in the New Statesman, Ziauddin Sardar writes that

The truth about the torture of detainees in Afghanistan and Iraq is simple. The Bush administration sanctioned it, the military deployed it, and the American public gave it a tacit nod of approval. Most of the people who were and are being tortured are innocent. And they are all Muslims ... There is a seamless connection between what happens in American society, the way society is represented by Hollywood, and the torture meted out by US soldiers abroad. In movies, torture is an everyday activity. ... Jack Bauer, the counter-terrorist agent in the TV series 24, tortures indiscriminately, not caring whether his victims are suspected terrorists, colleagues or teenaged girls. The relationship between American society and Hollywood is like a feedback loop. The extremity of one reinforces the other. ... This is why the soldiers at Abu Ghraib were not content simply to take photographs to send to the folks back home, but found it necessary to stage their atrocities as special events for the camera (Sardar 2005).

Communications scholar Roger Stahl argues that the nexus between Pentagon public relations and popular culture reflects a new turn in civilmilitary relations whereby citizens are enabled to "play soldier at a safe distance," through interactive means ranging from films to video games, toys, and even theme parks (Stahl 2010). This reprogramming of citizens as an extension of battlefield operations not only dovetails with the BushCheney campaign's core message, but it carries profound implications for American politics and even the nation's very identity.

\section{Ad Watch 3.0}

Glenn Leshner (2001) suggests that while much of the focus of ad watch journalism has been on "issues," candidate images are also critical to their electoral appeals, and scrutiny to such imagery may provide for a more engaging ad watch. Setting aside the limitations of the issue/image demarcation, Leshner is surely right in suggesting a broadening of the gaze of the ad watch. At the very least, the recognition that candidates are propagating claims about their character might prompt a more thoughtful discussion the strengths and weaknesses of both the candidates and the various archetypical character types. Perhaps more pointedly, observers may seek to probe more deeply into the fundamental underpinnings of candidates' personalities and psychological make-ups. Not that journalists haven't tried to do this at least since James David Barber's Presidential Character argued that personality shapes presidents, and that journalists ought do more to help voters understand potential presidents' personalities. Typically, at some point in the campaign, an analyst will produce a thoughtful, detailed assessment of one or more candidate's character. In the main in, however, it was very difficult for journalists to get much beyond the somewhat misleading brain tattoos they had regarding Gore (exaggerator), Kerry (flip-flopper), Bush 
(unflinching if not so smart), McCain (maverick hero) and Obama (rhetorically gifted and inspirational).

Yet, while the Bush campaign was incessant in picturing Bush as a steadfast leader in a time of terror, there were alternate readings of the same character traits. Perhaps most notably, (though little discussed in the media or elsewhere), Bush's steadfast stubbornness (and what some would see as wishful thinking) have all the earmarks of the "dry drunk," or individual who has substituted one obsession (in Bush's case, the war on terrorism) for another (the bottle) without going through a full therapeutic rehabilitation (see for example Schweizer and Schweizer 2004 on Bush's addictive personality). Whether or not this is actually the case with Bush is not the point so much as that such discussions need to become part of the palette from which candidate evaluations (and ad watches) are drawn.

So, too, with Senator McCain. If the conventional wisdom was that in 2000 reporters gave Vice president Gore no quarter, the same press corps swooned over the straight-talking maverick from Arizona, whose accessibility to the media and willingness to challenge GOP orthodoxy hit the proverbial "sweet spot" among many in the fourth estate. Despite McCain's steady tilt toward the GOP base from 2002 forward, McCain continued to enjoy the favorable if outdated adulation of reporters and the punditry throughout much of the 2008 campaign. Left largely untold was the story of McCain's dark side: temper tantrums, stubbornness, even a self-confessed immaturity. In a sense, the real McCain, rather than being an "anti-Bush" figure, was more Bush than Bush. A truthchallenged third generation child of privilege (John Sydney McCain III) whose family name saved him from various and sundry indiscretions, sober and not so much, that would have felled less privileged miscreants (Dickinson 2008).

Nor did the mainstream media engage Barack Obama's character in great detail. Perhaps misdirected by the candidate's early opposition to the war in Iraq and his background as a community organizer on the South Side of Chicago, the Illinois senator's centrist penchant for compromise and deal-making (so-called "Chicago-style" politics) was less noted. Such traits would come to the fore as soon as the transition period in late 2008, and seemed to define the president by the time of the debt ceiling debacle in the summer of 2011. It is likely that some of the reticence to engage Obama on character owed not just to the press but to his opponent. McCain, aides would say, had been on the receiving end of racially tinged Rovian attack politics (notably in the 2000 South Carolina primary) and would not be guilty of the same, at least as far as ads attacking the statements of Reverend Jeremiah Wright, Obama's former pastor, were concerned (Grann 2008). In fact, ABC News reported after the election that the McCain campaign did produce (but did not air) a campaign ad offering direct character comparison between POW McCain's steadfastness under enemy imprisonment and Obama's indifference to Wright's controversial sermons. It is possible had the ad been aired, it might have spurred a deeper inspection of the character question. 
On the other hand, the media's response to the McCain-Palin campaign's allegation that Obama had been "palling around with terrorists" offers little support for the notion that character assaults generate rigorous analysis of the character of the candidates. In fact, just as reporters willfully adopted the Bush-Quayle characterizations of "Willie" Horton in 1988, so too, was the McCain-Palin language adopted without resistance. Typical are the first two paragraphs from an October 5 report in the Los Angeles Times:

Englewood, Colo. - Republican vice presidential candidate Sarah Palin today accused Democrat Barack Obama of "palling around with terrorists" because of his association with a former 1960 s radical, stepping up the campaign's effort to portray Obama as unacceptable to American voters.

Palin's reference was to Bill Ayers, one of the founders of the group the Weather Underground. Its members took credit for bombings, including nonfatal explosions at the Pentagon and U.S. Capitol, during the tumultuous Vietnam War era four decades ago. Obama, who was a child when the group was active, served on a charity board with Ayers several years ago and has denounced his radical views and activities.

The reporter's language is clinical to the point of missing what was really going on. The story quotes Palin's incendiary assault, but fails to directly challenge its explosive core: that Ayers was a "terrorist." As FactCheck.org noted on October 10 regarding similar comments made by Senator McCain,"if McCain means the word 'terrorist' to invoke images of 9/11, he's being misleading; Ayers is no Osama bin Laden now, and never was." The Weather Underground did plant bombs in the 1960s. They targeted buildings, not people, sent warning in advance, and were designed to cause only property damage, not death. No doubt the Obama campaign was wise not to engage a debate on the tactics of a fringe group forty years prior, but if left the airwaves despoiled with McCain-Palin's arsonry. What's the difference between what the Weather Underground did and terrorism as practiced by bin Laden, et al? Life and death.

It is not that the media is unaware of the role of character assessment in the campaign. Indeed the phrase "master narrative" became a part of insider-speak, and journalistic watchdogs like the Pew Research Center's Project for Excellence in Journalism produced detailed studies of character in the campaign discourse (see Pew Research Center 2008a). Still, the Pew research indicates that of all campaign stories between January 1 and May 4, fully 78 percent focused on political concerns such as tactics, strategy and the horse race, while only 7 percent addressed personal issues. Moreover, much of the media's coverage of character telegraphed the messages of the competing campaigns. New York Senator Hillary Clinton was portrayed as experienced but also as representative of the politics of the past; Barack Obama as an agent of change but lacking in experience (Pew Research Center 2008b).

Yet such distinctions obscure a particular weakness in how the media covers campaigns. Charges that a candidate opposed body armor for the 
troops, for example, are likely to be viewed by the press through a policy frame rather than a character frame--despite the powerful resonance with character that is more likely to reflect how voters react to such charges. As policy, such issues typically carry greater ambiguity than they do as reflections of character. Consider how FactCheck.org addressed an exchange during the vice presidential debate over Sarah Palin's claim that Senator Obama "opposed funding for our troops in Iraq and Afghanistan ... after promising that he would not do so." Democratic vice-presidential nominee Joe Biden responded that "John McCain voted the exact same way. John McCain voted against funding the troops because of an amendment he voted against had a timeline in it to draw down American troops" (Commission on Presidential Debates 2008). FactCheck initially faulted Biden, but then issued the following correction:

Correction Oct 3: This article originally faulted Biden for saying that McCain had voted "the exact same way" as Obama on a controversial troop funding bill. We said that McCain was absent for the vote and so didn't vote at all. Biden was, however, correct.

McCain did vote against the troop-funding bill in question, H.R. 1591, on March 29, 2007, when it originally cleared the Senate. The vote to which we referred, and which McCain missed, was a later vote on the House-Senate compromise version of the same bill, on April 26, 2007. McCain opposed the bill, which Obama supported, because it contained language calling for withdrawal of troops from Iraq. Biden was responding to Palin's accusation that "Obama voted against funding troops." Obama voted for the bill March 29 and April 26, and then on May 24, 2007, following a veto by President Bush, Obama voted against a similar troopfunding bill, H.R. 2206, that lacked any withdrawal language. (FactCheck.org 2008b)

Lost in the byzantine legislative history is what Palin's charge suggests about Obama's character, and indeed, what making such a questionable incendiary remark says about her own character.

The quest for a more informed analysis of character is not without its own troubling conundrums. There is no agreement on which character type or personality traits are desirable. Traits desirable in one situation may not be so in another. Nor is character a dispositive indicator of behavior. Yet, like it or not, character and personal traits will no doubt continue to be a vital part of campaign discourse.

In the future, such personal analysis may increasingly turn on biological considerations, even while they, too, are variable indicators of potential and probability rather than determinative predictors. In an interview on "Bill Moyers Journal on PBS," Kathleen Hall Jamieson, perhaps the single most significant academic figure in the ad watch movement, argued for taking candidate's health issues seriously. Jamieson rejected simple concerns with John McCain's age, noting that "parental longevity has a small predictive effect" on longevity and that McCain's 95 year-old mother is "is mentally competent" and "articulate." By contrast, she noted, "we know that people who've smoked for a long 
time are more likely to die of a smoking related illness. They're more likely to have heart problems. They're more likely to die of lung cancer. Well, Barack Obama smoked until very recently" (Moyers 2008). The interview continued:

BILL MOYERS: Do we have a right to expect all the candidates to release their medical records, and their family histories?

KATHLEEN HALL JAMIESON: I believe we do. And I think it should be as central a question as our questions about their experience in office and their voting records. Some illnesses may carry genetic implications. Alzheimer's disease is one of them. President Reagan's mother had Alzheimer's disease. It's possible that in his second term, he was beginning to suffer some of those symptoms. It's possible that the assassination attempt may have made some of that worse. So there's some things that we want to ask about, not necessarily to disqualify a candidate, but because we want to understand the full implications of the health records that is available, and the implications, if any, for governance.

The trauma to this country if a president were to die in office is such that we have a right to know. And also, importantly, there have been major cover-ups in the past. The Kennedy campaign in 1960 effectively covered up Addison's disease. The Tsongas campaign effectively covered up the recurrence of cancer, and had Paul Tsongas, Senator Tsongas been elected president, he would have died in office. So we ought to, I think ask, what do we want to know when the age issue is raised? I think we want to know about health (Moyers 2008).

At one level, the implications of Jamieson's position are chilling. It seems she is optimistic in seeking admission of information about genetic makeup, "not necessarily to disqualify a candidate" when in fact that would seem to be a possibility if not the probable outcome of such disclosure. Society has yet to resolve such tensions, which have begun to crop up with greater frequency in employment and insurance settings. While medical research may be able to show patterns, linkages, and probabilities, they are far less than certainties. What of the cases of Reagan and Kennedy? Had either been disqualified on health grounds, would it have necessarily served the public interest? Could it be that no sooner had America finally abandoned the "whites only" White House then a whole new pattern of discrimination would take hold, one based even more precisely on genetics?

Realistically, it is unlikely that such a moment can be avoided. In a sense, however, the flaw in human intellect that causes vivid examples to override systematic evidence to the contrary may be the last refuge of human potential. Medical and genetic information may be uncontainable. While it is possible such knowledge may lead to costly prejudice, perhaps it will, instead, spawn an even greater appreciation for the human capacity to transcend one's "destiny," genetic or otherwise.

Truth and Consequence 
One of the great challenges in policing campaign discourse is discerning and communicating what is truly significant and consequential. Scholars have noted that the steady drip of ad watchers and fact checkers may leave voters with the misleading impression that candidates for office are inveterate dissemblers of falsehood and mistruth, while simultaneously allowing true whoppers to pass by virtually undistinguished from their garden-seed variety peers (Richardson 1998). By 2008, some ad cops had begun to tentatively address this challenge. Politifact.com's "truth-ometer" scored candidate claims into one of six categories as "true," "mostly true," "half true," "barely true," "false," and "pants on fire" (when "the statement is not accurate and makes a ridiculous claim"). The Washington Post's The Fact Checker used a "Pinocchio Test," with candidates' claims earning up to four "pinocchios" (for "whoppers") or the "prized Gepetto checkmark" for statements containing "the truth, the whole truth, and nothing but the truth."

Such efforts are potentially noteworthy improvements over earlier ad watch practice which, rather than putting the pieces of the puzzle together, served more to cut them up further still. Yet, there is room for additional refinement, for example, a running tally of each candidate's transgressions to date. Neither The Fact Checker nor Politifact's "truth-ometer" explictly tallied candidates cumulative scores in 2008. Such a scoreboard might discourage recidivist dissemblers by presenting a single metric reflecting upon their truthfulness. It would also allow a ready comparison across ad watchers, illuminating patterns of analysis and evaluation. Both The Fact Checker and Politifact's "truth-o-meter," presented ad watch evaluations which can easily be expressed in cumulative terms in 2008. (FactCheck did not produce numerical scoring of candidate claims in 2008).

Table I summarizes the "scoring" of candidate claims by The Fact Checker and Politifact's "truth-o-meter" that appeared between September 1 and Election Day. Higher scores represent greater deception or distortion. Stories addressed both claims made in ads and statements made by candidates. 


\section{TABLE I. AD WATCH AND STATEMENT SCORING 2008 PRESIDENTIAL ELECTION}

\begin{tabular}{lllll} 
& \multicolumn{2}{l}{$\begin{array}{l}\text { The Fact Checker } \\
\text { (Washington Post) }\end{array}$} & $\begin{array}{l}\text { "Truth-o-meter" } \\
\text { (Politifact.com) }\end{array}$ \\
(4-Point Scale) & McCain & \multicolumn{2}{l}{$\begin{array}{l}\text { (5-Point Scale) } \\
\text { Obama }\end{array}$} & McCain \\
Number of Entries & 10 & 12 & 21 & 20 \\
Total Points & 22 & 26 & 34 & 31 \\
Average Score & 2.2 & 2.2 & 1.6 & 1.6
\end{tabular}

Remarkably, both operations scored both candidates fidelity to the truth exactly evenly! Perhaps this is not so amazing given the intense scrutiny to press bias during political campaigns. Nonetheless, it is hard to imagine that during the course of a campaign in which the two candidates faced different strategic challenges and were attempting to mobilize different bases of support with vastly different perspectives on politics and the truth that this would be the case. Politifact's "truth-o-meter" did find a notable disparity in its "pants-on-fire" category for the most egregious distortions, issuing seven such ratings for McCain over the course of the entire campaign, but just two for Obama (Politifact 2008a).

Comparison of the content of the different ad watchers is complicated by the fact that it was actually relatively rare for both sites to adjudicate the same claims. Sometimes this was a matter of how a claim being scrutinized was framed. For example, consider the question of small business tax rates and Senator McCain's use of "Joe the Plumber," one Samuel Wurzelbacher who turned out to be neither a plumber nor named Joe. McCain's claim that Mr. Wurzelbacher's taxes would increase under Obama's plan was given three "pinocchios" by The Fact Checker, whereas Politifact's "truth-o-meter" scored instead Obama's claim that 98 percent of small business owners would see no tax hike as "true."

Perhaps more significantly, one can question how particular claims were scored. John McCain's claim that the federal government had spent $\$ 3.1$ million to "study the DNA of bears in Montana" (an example of the kind of earmark pork he denounced) was scored as "mostly true" by Politifact's analysis even though in fact McCain actually voted for the bill that included the earmark, after having introduced several amendments, including three targeting "pork," but none opposing the bear study (FactCheck.org 2007). At the same time, Politifact's basis for not crediting McCain with a fully true statement was that federal spending on the bear study had actually increased by $\$ 1.7$ million in the years since the bill originally passed than McCain said. One could say that in fact McCain's statement was more true than he claimed, if the point was that federal spending on sketchy appropriations was a significant budgetary problem! 
In short, in order for a running tally to be more meaningful, there would have to be some distinction between the candidates. That might very result from more rigorous attention to the degree of misstatement involved. In developing frameworks like the "pinocchio test" ad watchers have explicitly recognized that not all misstatements are created equal. Sometimes this can be readily quantified. Consider Obama's claim that 95 percent of the American people would get a tax cut under his proposals. Politifact's "truth-o-meter" rated the statement as "half-true," citing a nonpartisan study by the Tax Policy Center finding that 81 percent of tax filers would see tax reductions. Their conclusion: "[t]he difference between 81 percent and 95 percent is not insignificant. We rule his debate statement Half True" (Politifact 2008b). Mathematically, Obama's statement is actually 85 percent true, as it were, and not half (50 percent)-true. In its analysis of the first presidential debate, FackCheck.org noted misstatements by both candidates. Obama's, as in the above example, were off by perhaps, on average, 25 percent. McCain misstatements called out by FactCheck outnumbered Obama misstatements by at least 2-to-1. And their magnitude was often much greater, as in McCain's claim that earmarks had more than tripled, when FactCheck cited a study by the group Citizens Against Government Waste found a decrease in earmarks between 2003 and 2008 of 24 percent, amounting to an error of some 324 percent (FactCheck.org 2008c).

It is not just the degree of misstatement that is of concern, however, but also the consequences of that statement. One rough indicator of consequence is how many people are likely to be affected. The power of terrorism is that the pool of those affected is all inclusive. It could happen to anyone, giving it particular force. While debates over prescription drug costs for seniors can be seen passionately as life or death issues, and even given that we all hope to someday be old, the urgent consequence would seem lower than distortions about terror or the war on terror (or terror war). One potential formulation for a more precise measurement of misstatement would be:

Degree of distortion $\mathrm{x}$ significance/consequence of distortion $\mathrm{x}$ volume of repetition $=$ severity of infraction

It may be that rather than an interval level equation (a 100-point scale, for example), a categorical approach (high, medium, low, for example) would be more appropriate. Either way, some explicit consideration of each of the three factors would seem to be warranted.

\section{Merging truth, character and consequence: multimodal ad watching}

By the spring of 2012, the pillars of ad watch journalism have become well established. Politifact was awarded a Pulitizer Prize for National

Reporting for its coverage of the 2008 campaign. Its franchise extended from its Truth-o-Meter (with its "pants on fire" appellation for the claims it finds most egregious) to its "Obameter," "Flip-O-Meter," and GOPPledge-O-Meter), and in February 2012 it reported it had completed its 5,000 ${ }^{\text {th }}$ Truth-o-Meter fact-check. Kindred spirits "The Fact Checker" (from the Washington Post) and FactCheck.org are now veterans of 
several national election cycles as well. As of the 2012 campaign, the Annenberg Public Policy Center of the University of Pennsylvania (sponsor of FactCheck.org) has created FlackCheck.org, a video-based companion to the original. Notably, the site awards "orchids" to news programs that do an exemplary job of covering ads and web videos, "stinkweeds" to those who "slip up in the their treatment of ads," and "mixed bouquets" for those that do both. The proliferation of cable news outlets offers numerous venues for scrutinizing ad claims. Independent political groups flourish as well, some who engage advertising claims directly, including through counter-spots.

Politifact's finding that the Democratic charge that "Republicans voted to end Medicare" was the 2011 "Lie of the Year" offers much to recommend it, set against the standards suggested above. It targets a charge of wide relevance. The very act of naming one "lie" above all others the lie of the year carries recognition that not all mendacity is created equal, though it may take this tack too far. It is also at least arguably, if not definitively true, as Jamieson suggests, that Democratic exaggerations about Medicare and Social Security have for generations amounted to the longest running "Democratic deception" (Adair and Holan 2011). Without explicitly saying so, character is joined, both in defense of the attacked and against the attacker. Without question, "ending Medicare" is an incendiary charge, and when so many slightly modified alternative phrasings avail themselves, it is deliberately so. Candidates and parties should be called on that. Yet the move also merits some important criticism.

Politifact noted that the previous two annual "winners" also involved debate over health policy (in 2009, "death panels" and in 2010, the "government take over of health care"). The Medicare charge would appear to have more in common with the latter than the former. "Death panels," one of social media maven Sarah Palin's signature creations, was a whole cloth fabrication that 61 percent of the nearly 5,000 readerrespondents to a poll commissioned by Politifact identified as "Lie of the Year." Some 44 percent of readers agreed with the 2010 choice. Yet in 2011, Politifact and its reader-respondents differed as to the "Lie of the Year." Readers voted the claim that the American Recovery and Reinvestment Act of 2009 (ARRA), a.k.a. "the stimulus," created no jobs as lie of the year; the Medicare claim finished third.

Politifact reported that in 2011, for the first time, their poll became a target of fierce partisan combat, with both sides encouraging "voter" participation. Perhaps this is not only to be expected, but indicative of the flaw not in the partisans but in the judgment itself, or at least its sweeping nature. Exactly what purpose is served by designating a single "Lie of the Year?" Isn't there more than enough mendacity to warrant multiple awards? It is hard enough to resolve matters of bitter partisan dispute on their own merits. It is that much harder when attempting to draw from the cacophony of campaign talk a single offense above all others based a single dimension, "lying."

The Democratic transgression does not represent a claim unsupported by evidence or contrary to established knowledge. It is rather one of 
nomenclature. The Politifact judgment essentially rests on the argument that in privatizing Medicare (by providing premium support or vouchers), the Ryan/G.O.P. plan did not end Medicare since there would still be a program called Medicare. Had the Democrats and others only said "end Medicare as we know it," they would have avoided the opprobrium, Politifact acknowledged in reviewing the charge when made by Senator Sherrod Brown of Ohio (Politifact 2011a). This, however, is a rather slender distinction upon which to base such a freighted judgment as "Lie of the Year." Politifact acknowledged that costs to seniors would leap from 25 percent of expenses to 68 percent under the Ryan plan, and that the Republican approach amounted to "fundamental change" by replacing an entitlement with "premium support."

Politifact maintains this is a difference in degree and not of kind, but reasonable minds may quibble. One could argue that nearly trebling the share of costs born by seniors (and concomitantly reducing the share born by Medicare by two-thirds) renders the "end Medicare charge"

mathematically closer to the truth than "keeping Medicare" as it is would be. What if 99 percent of expenses were to be born by seniors? Would it still be Medicare then?

For Politifact, "ending” Medicare means zero Medicare or no program called Medicare. Anything less is false. Zero jobs from the ARRA means zero jobs. Any non-zero job gain falsifies the statement. While there is a superficial certitude and clarity to this approach, it appears ill-suited to engage political discourse where the meaning of language itself and the uncertain consequences of policy are both highly contested. Rather than helping voters put the pieces of the puzzle together, this microsemanticism cuts the pieces up into ever smaller slivers, running the risk of losing the political forest for the linguistic trees.

Consider Politifact's (2012) rating of a Mitt Romney campaign mailer's charge that "Since the passage of Obama's stimulus package, over 1 million additional jobs were lost and nearly 25 million Americans are out of work, are stuck in part-time work, or have given up looking," as "half-true." The designation is literally true but it does not seem to meaningfully describe the significance of what Politifact's own analysis points to. The first eleven paragraphs of the story essentially "bear out" Romney's claims. Before the ARRA, there were 132.8 million jobs, after 131.7 million. Only then does the article pose the question, "is Obama to blame?" The next ten paragraphs present overwhelming evidence that the ARRA produced millions of jobs, with independent estimates ranging from 1.3 to as many as 2.5 million jobs created or saved. The implicit priority of the piece seems skewed. No one is contesting the employment data. The political question (raised by the Romney charge) is what it means, and more specifically what the president's policies have or have not accomplished. To be fair, Politifact also gave a statement from a National Republican Senatorial Committee ad that the stimulus created "zero jobs" its "pants-on-fire" designation for full-throated dishonesty (Politifact 2011b). There has to be some better way to properly distinguish among such claims if the project is to be more useful. 
At its worst, the fundamental problem with Politifact is that all too often it becomes bogged down in virtually meaningless definitional minutiae used to justify stark assessments of mendacity. In emphasizing literalism, the site's journalists fail to clarify fundamental political issues while at the same time criminalizing robust political debate. In 2012, the site rated an MSNBC promotional ad "mostly false" for claiming that critics of the GI Bill (passed in June of 1944) called it "welfare." In their analysis, Politifact noted that critics of the bill likened it to "the bane of the British Empire, ... the dole system," claimed it would reward "the lazy and "chisely' types of veterans," described it as more of a "relief" act than an educational one, and that the president of the University of Chicago, Robert Maynard Hutchins, warned that colleges and universities would be converted into "hobo jungles." But, as the scholars quoted by Politifact duly noted, it would be "incorrect to say the critics called the proposal welfare." This toxic literalism serves no positive purpose.

Now consider Politifact's take on MSNBC host Rachel Maddow's claims about the budget situation in Wisconsin. In February, 2011, the site rated Maddow's statement that Wisconsin had a projected budget surplus "false." Politifact acknowledged that a memo prepared by the director of Wisconsin's nonpartisan Legislative Fiscal Bureau stated "a general fund gross balance of $\$ 121.4$ million and a net balance of $\$ 56.4$ million." The site claimed, however, that "unpaid bills" and "expected shortfalls in programs" meant the budget was actually in deficit. Politifact does not state, however, whether the overdue bills and projected shortfalls are actually part of the budget. What happened to Politifact's characteristic literalism? The piece quotes the memo's author as saying he didn't want "to presume what legislative or other action will be taken to address the potential shortfalls" (emphasis added). More to the point, the central claim in Maddow's piece was not that the budget was balanced (indeed she notes the very same deficit number Politifact relies upon, albeit linking it suggestively with the size of corporate tax breaks intiated by Wisconsin Governor Scott Walker that Politifact points out will not take effect until the following biennial budget). Rather, it was that budgetary constraints did not justify the anti-union legislation Wisconsin was moving to adopt. In addition to the budget memo, Maddow pointed out that the budget included other new provisions that would swell the deficit. For better or worse, the argument that the Wisconsin collective bargaining measures represented a partisan attack on the opposition base and not fiscal necessity is not the type of claim Politifact typically engages and it did not do son in connection with the Maddow piece. Politifact may be right, but only by training its vision so narrowly as to miss the true bone of contention.

Perhaps some progress can be made through a more explicit taxonomy of deceptions, distortions and lies. Some transgressions involve statements found to run contrary to the preponderance of evidence, for example claims denying climate change or evolution, or suggesting that preventative care saves money. Other claims could be categorized as misstatements of an opponent's position. Some might represent emotionally "loaded" language (such as "ending Medicare"). Others represent technical distortions, such as those using audiovisual editing to 
create false impressions. As noted above, some can be seen as policy disagreements, while other charges, ostensibly couched as policy, truly function more as character assaults. In short, the problem with the "lie of the year" approach is that it invites a summary judgment where a range of specifics would be more useful. It is not just that the claim is distorted or false, but how so that requires elaboration.

More can be done. By early 2012, Politifact had begun to offer a smartphone app with features including a running tally on candidates' performance for the primary period. Without some running tally or scoreboard, candidates or groups may find little deterrence in condemnatory ad watches, but a simple total may not provide viewers sufficient information. The sheer profusion of advertising and communications claims make it inevitable that even severe infractions may blend into the cacophony of the campaign. Politifact's website is already bloated with dozens of individual analyses, presumably presented chronologically, leaving visitors to the site to guess as to what is really important as opposed to most recent (though one is reticent to fault journalists who by definition traffic in the present for failing to re-process the past).

The sports pages may offer a useful model for the fact checkers. There, for any given sport, one often finds several different categories of "league leaders." Or better yet, the Academy Awards ceremony with its many categories. The latter model could naturally accommodate audiovisual production values and evocation of popular cultural forms commonly found in ads like horror, satire, and biography. It could include a categories related to various emotions such as fear. In including all manner of mistruth under the same umbrella, ad watch metrics run the risk of serious distortion. It may be more useful to group transgressions by type, comparing candidates accordingly. Simply "naming an award" for best (or worst) use of scare tactic or worst denial of the preponderance of evidence can also help educate readers about the different extant types of distortions and deceptions. There is plenty enough mendacity to go around, it would seem, and there is no need to limit analysis to but a single metric.

The Medicare charge falls into the category of definition and nomenclature. The ARRA charge is an example of denial of the preponderance of evidence or a statement without evidence. At the same time, the Medicare charge is a potentially emotionally brutal one aimed squarely at a broad swath of vulnerable voters.

The ARRA charge is directed specifically at Barack Obama, or presumably sympathetic Democratic legislators and candidates. It is an argument about the effectiveness of a policy overtly and implicitly a judgment of an impotent character or worse (corrupt). Indeed it represents a direct assault on Obama's response to the greatest of the multitude of crises that confronted him, and is not without emotional baggage too.

Perhaps the most vexing challenge in building a better ad watch for the $21^{\text {st }}$ century is engaging the way the audiovisual and narrative elements combine to present arguments spanning reason and emotion, 
often blurring character and policy in the process. As noted above, the audiovisual grammar developed by Jamieson's team is primarily an audiovisual way of engaging textual argumentative claims. It was not designed to engage audiovisual arguments. Such an approach would be most welcome.

This task does not seem one that the current institutional pillars of ad watch journalism are well-poised to take up. There is much subjectivity in the kind of narrative and indeed mythic resonance of political advertising, a terrain many mainstream journalists remain reluctant to cross. The technology and skills required to devise and deploy an audiovisual counter-arsenal, moreover, seem likely to escape all of today's ad watch avatars.

One technique that can be used to counter the audiovisual evocation of culturally resonant communication is to break down the production into its component parts. Nelson and Boynton (1997) "deconstruct" a campaign ad in this fashion, showing how audiovisual elements like black-and-white imagery, the howling of the wind and ominous music combine to communicate horror (see also Richardson 2003 for experimental construction of horror ads). In 2012, FlackCheck.org created a prototypical attack ad taking quotes from Lincoln's Gettysburg Address out of context to suggest that the $16^{\text {th }}$ president had said Americans had "died in vain," and that he believes that America will "perish from the earth."

"Cable" news outlets such as MSBNC, Current TV, and Fox News Channel may turn out to be the most likely frontier for extending the next generation of ad watch praxis. They may possess the technical, intellectual, and financial resources to pursue the project. Yet they will not be alone. Independent and partisan groups and even lone-wolf YouTube sensations now command noteworthy capabilities and audience.

The full array of ad watch combatants was on vivid display following the airing in late 2011 of a spot produced by GOP presidential candidate Mitt Romney titled, "Believe in America." The ad shows President Obama saying, "if we keep talking about the economy, we'll lose." The video clip in the Romney ad actually dated to 2008, and was edited to make it appear that Obama was speaking about his campaign, when in fact he had been quoting an aide to the McCain campaign. TV analysts dutifully played the full quote, upbraiding the Romney team for deceitful and dishonest tactics. Unsurprisingly, they often adopted much of the ad's narrative and audiovisual framing even in critique, and some looped sound and images from the ad as background. While roundly condemning the technical distortion of the ad, few if any challenged the underlying challenge to Obama's economic record, which by that time had produced nearly two consecutive years of private sector job growth.

Perhaps the most effective countermeasure, however, came from a counter ad, "Mitt Romney in His Own Words*," produced by the advocacy group ThinkProgress, using the same technique the Romney ad had to make it appear that Romney had made outlandish statements, culminating in the asterisked punch line, "All quotes accurate by the 
standards of Mitt Romney.” It, too was included in cable news stories about the campaign. It is closely akin to the type of thing The Daily Show with Jon Stewart excels at.

There is, in short, no lack of participants in the struggle to contest questionable campaign communication. The success of fact-check journalism stands as notable example of the profession not only adapting but thriving in the face of accelerated change in communications technology. As we gaze into the future, we may expect that Ad Watch 3.0 will be: interactive and communal (social), multimedia (audio, video, and hyperlink), multiargumentative (policy, metaphor, genre, myth, and character) and multicontested. Several specific reforms have been identified above, including taking audiovisuals much more seriously, addressing claims of character, more precisely quantifying the degree of misstatement, and producing a running tally or scoreboard across multiple categories of distortions and deceptions to offer a series of cumulative measures of a candidate's fidelity to the truth over the course of a campaign.

\section{References}

Adair, Bill and Angie Drobnic Holan. 2011. "Lie of the Year 2011: Republicans Voted to End Medicare.” Politifact.com/Tampa Bay Times. Accessed online at http://www.politifact.com/truth-ometer/article/2011/dec/20/lie-year-democrats-claims-republicansvoted-end-me/ on February 17, 2012.

Ansolabehere, Stephen, and Shanto Iyengar. 1996. "Can the Press Monitor Campaign Advertising? An Experimental Study." Harvard International Journal of Press/Politics 1 (Winter):72-86.

. 1995. Going Negative: How Political Advertisements Shrink and Polarize the Electorate. New York: The Free Press.

Balz, Dan. "Bush Begins to Stress Differences With Gore; Tax Plan Pitched to Middle-Class Families." Washington Post. September 19:A8.

Bennett, Courtney. 1997. "Assessing the Impact of Ad Watches on the Strategic Decision-Making Process: A Comparative Analysis of Ad Watches in the 1992 and 1996 Presidential Elections." American Behavioral Scientist 40(8):1161-1182.

Brader, Ted. 2006. Campaigning for Hearts and Minds: How Emotional Appeals in Political Ads Work. Chicago: University of Chicago Press.

Broder, David. 1996. "Negative Ads Proved Cause of Voter Anger." The Sunday Oregonian. January 14:EO3. . 1990. "A Five Point Plan to Return Campaigns to Voters." Washington Post Service (January 21).

Clarke, Richard A. 2005. "Ten Years Later." Atlantic Monthly. 295(1) January/February.

Commission on Presidential Debates. 2008. Debate Transcript: The Biden-Palin Vice Presidential Debate. 
http://www.debates.org/pages/trans2008b.html. Accessed January 9, 2009.

Cooper, Michael. 2000. "In Harshest Attack Yet, Cheney Accuses Gore of Fabrications." New York Times. September 20:A22.

Dickinson, Tim. 2008. "Make-Believe Maverick: A closer look at the life and career of John McCain reveals a disturbing record of recklessness and dishonesty." Rolling Stone. October 16.

Dowd, Maureen. 2006. "Looking for a Democratic Tough Guy, or Girl." New York Times. January 18:19.

FactCheck.org 2008a. "Our Disinformed Electorate." December 12. http://www.factcheck.org/specialreports/our_disinformed_electorat e.html. Accessed online January 10, 2009.

FactCheck.org. 2008b. "Fact Checking the Biden-Palin Debate." October 3 (updated October 13). http://www.factcheck.org/elections2008/factchecking_biden-palin_debate.html. Accessed online January 9, 2009.

FactCheck.org. 2008c. "FactChecking Debate No. 1." September 27, 2008 (updated October 13). http://www.factcheck.org/elections2008/factchecking_debate_no_1.html. Accessed online January 10, 2009.

FactCheck.org 2007. "'Outrageous Exaggerations." November 20. http://www.factcheck.org/outrageous_exaggerations.html. Accessed January 10, 2009.

Frankel, Max. 1996. "Word and Image: Let Lying Dogs Sleep." New York Times Magazine January 14:18.

Grann, David. 2008. "The Fall: John McCain's Choices." New Yorker November 17:65.

Hari, Johann. 2006. "TV's Top Rated Torturers." The Independent (London). February 9:12.

Hastie, Reid, and Bernadette Park. 1986. "The Relationship between Memory and Judgement Depends on Whether the Judgement Task is Memory Based or On-line." Psychology Review 93 (July):258-268.

Jamieson, Kathleen Hall. 1992. Dirty Politics: Deception, Distraction, and Democracy. New York: Oxford University Press.

Jamieson, Kathleen Hall and Karlyn Kohrs Campbell. 2001. The Interplay of Influence: News, Advertising, Politics, and the Mass Media (5th ed.). Belmont, CA: Wadsworth Thomson Learning.

Jamieson, Kathleen Hall and Joseph N. Cappella. 1997. "Setting the Record Straight: Do Ad Watches Help or Hurt?" Harvard International Journal of Press/Politics 2(1):13-22.

Johnson, Glen. 2000. "Prescription Story is a Pill for Gore." Boston Globe. September 19:A7.

Kaid, Lynda Lee, John C. Tedesco and Laurie M. McKinnon. 1996. "Presidential Ads as Nightly News: A Content Analysis of 1988 and 
1992 Televised Ad Watches." Journal of Broadcasting and Electronic Media 40:279-303.

Kelly, Michael. 2000. "Flapping Furiously." Washington Post. September 20:A33.

Kurtz, Howard. 2000. "Bush Uses Dog Tale to Bite Gore." Washington Post. November 1:A14.

Lakoff, George. 1996. Moral Politics: How Liberals and Conservatives Think (2d ed.). Chicago: University of Chicago Press.

Leshner, Glenn. 2001. "Critiquing the Image: Testing Image Adwatches as Journalistic Reform." Communication Research 28(2) April:181-207.

Marks, Peter. 200o. "Focusing on Gore Hyperbole." New York Times. November 1:A28.

McKinnon, Laurie Melton and Lynda Lee Kaid. 1999. "Exposing Negative Campaigning or Enhancing Advertising Effects: An Experimental Study of Adwatch Effects on Voters' Evaluations of Candidates and Their Ads." Journal of Applied Communication Research 27:217-236.

McKinnon, Laurie Melton, Lynda Lee Kaid, C.K. Acree and J. Mays. 1996. "Policing Political Ads: An Analysis of Five Leading Newspapers' Responses to 1992 Political Advertisements." Journalism and Mass Communication Quarterly 73:66-76.

Moyers, Bill. 2008. "Bill Moyers Journal: Transcript (February 8)." http://www.pbs.org/moyers/journal/o2082008/transcript3.html. Accessed online January 9, 2009.

Nelson, John S. and G.R. Boynton. 1997. Video Rhetorics: Televised Advertising in American Politics. Urbana, IL: University of Illinois Press.

Orr, Christopher. 2006. "Kiefer Madness." The New Republic. May 22:16.

O’Sullivan, Patrick B. and Seth F. Geiger. 1995. Newspaper Truthboxes and Political Attack ads: Does the Watchdog Bite? Journalism Quarterly 72:771-785.

Painter, Chad and Louis Hodges. 2010. "Mocking the News: How the Daily Show with Jon Stewart Holds Traditional Broadcast News Accountable." Journal of Mass Media Ethics 25(4):257-274.

Papper, Bob. 2007. “TV Adwatch Stories on the Rise.” Annenberg Public Policy Center. November 9. Accessed online at http://www.annenbergpublicpolicycenter.org/Downloads/Political C ommunication/FactCheck/20071109 FactCheckingJournalism/2007 1109 fcj TV Survey Report.pdf on March 4, 2012.

Parry, Robert. 2000. "He's No Pinocchio: How the Press has Exaggerated Al Gore's Exaggerations." Washington Monthly 32(4), April:23-28.

Pew Research Center. 2008a. "Character and the Primaries of 2008." http://www.journalism.org/node/11266; accessed online January 8, 2009.

Pew Research Center 2008b. "Beyond the Master Narratives." 
http://www.journalism.org/node/11276; accessed online January 8, 2009.

Pfau, Michael and Allan Louden. 1994. "Effectiveness of Adwatch Formats in Deflecting Political Attack Ads." Communication Research 21(3):325-341.

Politifact.com. 2012. "Mitt Romney says since Obama's stimulus package over 1 million jobs were lost."

http://www.politifact.com/florida/statements/2012/jan/11/mittromney/romney-says-obamas-stimulus-package-over-1-million/.

Accessed online February 18, 2012. . 2011a. "U.S. Senator Sherrod Brown Warns There is a Republican Plan to End Medicare." http://www.politifact.com/ohio/statements/2011/jun/27/sherrodbrown/us-sen-sherrod-browns-campaign-warns-there-republi/. Accessed online February 17, 2012. 2011b. "National Republican Senatorial Committee Ad Says Stimulus Created 'Zero Jobs'.” http://www.politifact.com/virginia/statements/2011/oct/21/national -republican-senatorial-committee/national-republican-senatorialcommittee-ad-says-s/. Accessed online February 18, 2012.

. 2008a. "Statements we say are Pants on fire!" http://www.politifact.com/truth-o-meter/rulings/pants-fire/. Accessed online January 10, 2009.

. 2008b. "Under Obama's tax plan, "95 percent of you will get a tax cut." http://www.politifact.com/truth-ometer/statements/750/. Accessed online January 10, 2009.

Rich, Frank. 2005. "We'll Win This War -- On '24'." New York Times. January 9, section 2:1.

Richardson, Glenn W. Jr. 2003. Pulp Politics: How Political Advertising Tells the Stories of American Politics. Lanham, MD: Rowman and Littlefield.

. 2002. "Visual Storytelling and the Competition for Political Meaning in Political Advertising and News in Campaign 2000." American Communication Journal 5(3) Spring. . 1998. "Building a Better Ad Watch: Talking Patterns to the American Voter." Harvard International Journal of Press/Politics 3(3):76-95.

Robinson, Walter V. 2000a. "Gore Misstates Facts in Drug Cost Pitch." Boston Globe. September 18:A6. Costs." Boston Globe. September 22:A1.

Rutenberg, Jim. 2004. "Bush Campaign Replaces Ad that Had Doctored Images." New York Times. October 29.

Sardar, Ziauddin. 2005. "The Holiday Snaps. Abu Ghraib wasn't the Fault Just of US Politicians and Soldiers. Torture, Glamourised by 
Hollywood, is Now Intrinsic to American Life." New Statesman. March 7.

Schweizer, Peter and Rochelle Schweizer. 2004. The Bushes: Portrait of a Dynasty. New York: Doubleday.

Seelye, Katherine Q. 200o. "Under Attack, Gore Reshapes Censure of Drug Industry." New York Times. September 21:A26.

Shapiro, Walter. 200o. "'Untruthful' Label Could Dog Al Gore." USA Today. September 20:15A.

Shrum, Robert. 2007. No Excuses: Concessions of a Serial Campaigner. New York: Simon and Shuster.

Stahl, Roger. 2010. Militainment, Inc.: War, Media, and Popular Culture. New York: Routledge

Sternbergh, Adam. 2006. "Missions Accomplished: If the Public is Wary of the Real-life War, Why are Viewers Eating Up Shows about a Gung Ho Military?" New York Times Magazine. April 10.

Tufte, Edward R. 1997. Visual Explanation: Images and Quantities, Evidence and Narrative. Chesire, CT: Graphics Press.

Wasson, David. 2000. "Gore Touts His Drug Plan in Florida." Tampa Tribune. August 29:1

Weaver Lariscy, Ruth Ann and Spencer F. Tinkham. 1999. "Watching the Adwatch: Does It Make a Difference? Should It?" Paper presented to the Political Communication Division of the International Communication Association, San Francisco, CA, May.

West, Darrell M. 2005. Air Wars: Television Advertising in Election Campaigns, 1952-2004. Washington, D.C.: CQ Press.

\footnotetext{
Science and Politics 25 (March):74-77.
} 